\title{
Intron retention and rhythmic diel pattern regulation of carotenoid cleavage dioxygenase 2 during crocetin biosynthesis in saffron
}

\author{
Oussama Ahrazem $^{1,2}$ - Angela Rubio-Moraga ${ }^{1} \cdot$ Javier Argandoña-Picazo $^{1}$. \\ Raquel Castillo ${ }^{3} \cdot$ Lourdes Gómez-Gómez $^{1}$
}

Received: 16 November 2015/Accepted: 22 March 2016/Published online: 12 April 2016

(C) The Author(s) 2016. This article is published with open access at Springerlink.com

\begin{abstract}
The carotenoid cleavage dioxygenase 2, a new member of the CCD family, catalyzes the conversion of zeaxanthin into crocetin-dialdehyde in Crocus. CCD2 is expressed in flowers, being responsible for the yellow, orange and red colorations displayed by tepals and stigma. Three CsCCD2 genes were identified in Crocus sativus, the longest contains ten exons and the shorter is a truncated copy with no introns and which lacks one exon sequence. Analysis of RNA-seq datasets of three developmental stages of saffron stigma allowed the determination of alternative splicing in $C s C C D 2$, being intron retention (IR) the prevalent form of alternative splicing in $C s C C D 2$. Further, high IR was observed in tissues that do not accumulate crocetin. The analysis of one $C s C C D 2$ promoter showed cis-regulatory motifs involved in the response to light, temperature, and circadian regulation. The light and circadian regulation are common elements shared with the previously characterized $C s L y c B 2 a$ promoter, and these shared common cis-acting elements may represent binding sites for transcription factors responsible
\end{abstract}

Electronic supplementary material The online version of this article (doi:10.1007/s11103-016-0473-8) contains supplementary material, which is available to authorized users.

Lourdes Gómez-Gómez

Marialourdes.gomez@uclm.es

1 Departamento de Ciencia y Tecnología Agroforestal y Genética, Facultad de Farmacia, Instituto Botánico, Universidad de Castilla-La Mancha, Campus Universitario s/n, 02071 Albacete, Spain

2 Fundación Parque Científico y Tecnológico de Castilla-La Mancha, Campus Universitario s/n, 02071 Albacete, Spain

3 VITAB Laboratorios, Polígono Industrial Garysol C/Pino, parcela 53, La Gineta, 02110 Albacete, Spain for co-regulation of these genes during the development of the stigma in saffron. A daily coordinated rhythmic regulation for $C s C C D 2$ and $C s L y c B 2 a$ was observed, with higher levels of mRNA occurring at low temperatures during darkness, confirming the results obtained in the in silico promoter analysis. In addition, to the light and temperature dependent regulation of $C s C C D 2$ expression, the apocarotenoid $\beta$-cyclocitral up-regulated $C s C C D 2$ expression and could acts as a mediator of chromoplast-to-nucleus signalling, coordinating the expression of $C s C C D 2$ with the developmental state of the chromoplast in the developing stigma.

Keywords Apocarotenoid - CCDs · Crocetin · Intron retention $\cdot$ Promoter $\cdot$ Saffron $\cdot$ Splicing

\section{Introduction}

Carotenoids are widespread highly hydrophobic compounds that have been isolated from many living organisms. However, their biosynthesis is restricted to plants, some bacteria and fungi. In plants, yellow, orange, and red colours provided by carotenoids accumulate in the chromoplasts of flowers and fruits. In these tissues, carotenoids act to attract pollinators and agents of seed dispersal. In addition to carotenoids, their oxidative and enzymatic cleavage products called apocarotenoids, are crucial for various biological processes in plants, such as stress responses, regulation of growth and development, and in the interaction with their environment (Al-Babili and Bouwmeester 2015; Walter and Strack 2011). For humans, some apocarotenoids synthesized by plants have an important economic value, due to their very potent aroma (e.g. $\beta$-ionone and safranal) and their pigmentation 
capacity (e.g. crocin and bixin) (Gómez-Gómez et al. 2010; Winterhalter and Rouseff 2001).

Whereas carotenoid biosynthesis is limited to plants, some bacteria and fungi, apocarotenoids are present in practically all organisms. A group of enzymes called carotenoid cleavage dioxygenases are responsible for catalyzing the cleavage reactions on carotenoids (Sui et al. 2013). In plants, there are two different groups of carotenoid cleavage dioxygenases (CCDs), the NCED enzymes catalyze the first step towards abscisic acid (ABA) biosynthesis (Schwartz et al. 1997) and the CCD enzymes that have more divergent activities and catalyze the cleavage of a variety of carotenoid substrates at specific double bond positions (Auldridge et al. 2006). NCEDs and CCDs enzymes belong to an ancient family that employs a nonheme iron cofactor to activate molecular oxygen for insertion into a carbon-carbon double bond of the carotenoid polyene. Five subfamilies have been defined in the CCD plant family; CCD1, CCD2, CCD4, CCD7 and CCD8, which differ in their substrate and regioselectivity. Members from the CCD1, CCD4, CCD7 and CCD8 subfamilies have been identified in all the high plant genomes sequenced up to date (Ahrazem et al. 2010b), being CCD2 an exception, with members only identified in Crocus sativus and in other Crocus species (Ahrazem et al. 2016; Frusciante et al. 2014). The CCD2 enzymes are closely related to the CCD1 subfamily. But while CCD1 enzymes showed a broad substrate and double bond specificity (Ilg et al. 2014; Walter and Strack 2011), CCD2 enzymes displayed a restricted specificity on substrates and double bond recognition (Frusciante et al. 2014). CCD2 has been identified in C. sativus (CsCCD2) as the enzyme responsible for the cleavage of zeaxanthin at $7,8\left(7^{\prime}, 8^{\prime}\right)$ positions to produce crocetin dialdehyde $(\mathrm{C} 20)$ and hydroxy- $\beta$-cyclocitral (C10). The enzyme also cleaves lutein as well as 3 -OH- $\beta$-apocarotenals at the 7,8 position, suggesting the requirement for a 3-OH- $\beta$-ring at the proximal end of the substrate molecule (Frusciante et al. 2014). In addition, CCD1 and CCD2 enzymes also differ in their location, while CCD1 enzymes are cytosolic, CCD2 enzymes are localized in plastids (Ahrazem et al. 2016).

The flower of $C$. sativus has a long red divided stigma, characterized for a high content in apocarotenoids that when processed constitute the saffron spice, one of the oldest spices used as flavouring and colouring agent (Ahrazem et al. 2015b). These apocarotenoids are the products of CCD2 activity, crocetindialdehyde and hydroxy- $\beta$-cyclocitral, which are the substrates of aldehyde dehydrogenases and the resulting products are further glucosylated generating crocins and picrocrocin, which after thermal degradation is transformed into the odouractive volatile safranal (Moraga et al. 2004, 2009). Crocins and safranal are responsible, respectively, of the colour and aroma properties of the saffron spice.

The accumulation of carotenoid precursors and saffron's apocarotenoids in $C$. sativus stigmas have been previously studied (Castillo et al. 2005; Moraga et al. 2009; Rubio et al. 2008), and it has been shown that transcriptional regulation of two chromoplast-specific carotenogenic genes, $\beta$-carotene hydroxylase $(\mathrm{CsBCH})$ and the stigmaspecific lycopene cyclase $(C s L y c B 2 a)$, are controlling the carotenoid pool for apocarotenoid biosynthesis (Ahrazem et al. 2010a). As carotenoids, crocins and picrocrocin accumulation in saffron stigma are spatially and temporally regulated. These apocarotenoids begin to accumulate in the stigma at very early developmental stages (Moraga et al. 2009), coincident with the expression levels of CsCCD2 (Frusciante et al. 2014; Rubio et al. 2008), which levels decline when the stigma is fully developed and the apocarotenoid levels have reached a plateau, starting thereafter its mobilization from the senescent stigma (Rubio-Moraga et al. 2010). The regulatory mechanisms that control carotenoid and apocarotenoid accumulation remain poorly understood in saffron. In fact, to date no regulatory genes directly controlling carotenoid or apocarotenoid biosynthetic gene expression have been isolated. Nonetheless, it is known that a major driving force for apocarotenoids production in saffron is the transcriptional regulation of genes encoding lycopene cyclase, $C s L y c B 2 a$, the enzyme catalyzing zeaxanthin production, $C s B C H 1$, and $C s C C D 2$. Consistently, the burst in apocarotenoids biosynthesis that occurs in the stigma of saffron is correlated with a very fast up-regulation of $C s L y c B 2 a$ and $C s C C D 2$ transcripts (Ahrazem et al. 2010a; Frusciante et al. 2014). Thus, the developmental and concerted regulation of carotenogenesis and crocetin biosynthesis in saffron stigma suggest the presence of commom cis-regulatory elements in the promoter regions of these genes.

In this article, we address the evolutionary relationships of CsCCD2 with others plants CCDs by examination of gene architecture. For such a purpose, the genomic sequences and organization of $C s C C D 2$ are described, and these sequences were compared to $C C D 1$ sequences from angiosperms and gymnosperms in the databases. Taking advantage of transcriptome data from early developmental stigma stages and other saffron tissues, we identify differences in CsCCD2 transcripts. We found that tissues that do not accumulate crocetin exhibited increased levels of intron retention in $C s C C D 2$ transcripts relative to stigma tissue. Further, a $C s C C D 2$ promoter region was isolated and compared with the previously identified $C s L y c B 2 a$ promoter and a new mechanism controlling the expression during stigma development and crocetin accumulation is discussed. 


\section{Materials and methods}

\section{Plant material and treatments}

Corms of $C$. sativus donated by the Fundación Valeriano González (Albacete, Spain,) were used throughout the experiments. $C$. ancyrensis and $C$. cartwrightianus were collected from plants growing in the Botanical Garden of CLM (Albacete, Spain). Stigmas were collected at the developmental stages previously described (Rubio et al. 2008) and frozen in liquid nitrogen and stored at $-80^{\circ} \mathrm{C}$ until required.

To determine the regulation of $C s C C D 2$ three sets of experiments were designed. The first experiment was conducted to investigate the day/night regulation of $C s C C D 2$. Stigmas in the orange stage (Rubio et al. 2008) were collected at different times from 16th to 18th October 2015, from 100 plants growing under field conditions. Humidity and temperature in the growing area were recorded during the selected period. In the second set of experiments, 100 saffron corms were placed on individual pots; 50 pots were covered simulating complete dark conditions while the other 50 pots were uncovered. Stigmas at different developmental stages from yellow, orange and red were collected at the same time from both batches. The third set of experiments was designed to determine the temperature and light regulation of $C s C C D 2$. Flowers buds with yellow, orange and red stigmas were collected from four independent biological replicates and were placed in 24-well plates containing $1 \mathrm{ml}$ distillate water. One plate was placed during $24 \mathrm{~h}$ at $37^{\circ} \mathrm{C}$, other at $8{ }^{\circ} \mathrm{C}$, other at $20^{\circ} \mathrm{C}$ in continuous light, other at $20{ }^{\circ} \mathrm{C}$ in continuous dark and the last one in a chamber at $20{ }^{\circ} \mathrm{C}$ with $12 \mathrm{~h}$ light/dark cycles, this last treatment was used as control. Further an additional batch of stigmas growing in control conditions were treated with $\beta$-cyclocitral $(0.1 \mu \mathrm{l}$ of a pure compound) during $24 \mathrm{~h}$.

\section{Isolation of promoter sequence}

Genomic DNA was prepared from $C$. sativus leaves by using the i-genomic Plant DNA extraction kit (iNtRON Biotechnology, Sangdaewon-Dong, Korea). The CsCCD2 upstream flanking sequences were isolated with the GenomeWalker Universal Kit (BD Biosciences, Palo Alto, CA, USA). The genomic DNA was digested with four alternative restriction enzymes (DraI, EcoRV, StuI and PvuII) and separately ligated with the adaptors provided by the manufacturer to obtain four restriction fragment libraries. PCRs were carried out using gene-specific primers (Table 1) based on the cDNA sequence obtained and adapter primers (AP1 and AP2). All PCR reactions were performed using Advantage 2 Polymerase mix (BD Biosciences, Palo Alto,
CA, USA). The reaction products were ligated to pGEM-T with the TA Cloning Kit (Promega Corporation, Madison, USA). The ligated DNA was transformed into $E$. coli strain JM109. For each amplification round, 20 colonies were picked individually, amplified and the plasmid DNA extracted using a DNA Plasmid Miniprep Kit (Promega, Madison, WI, USA). Plasmids were sequenced using an automated DNA sequencer (ABI PRISM 3730xl, Perkin Elmer) from Macrogen Inc. (Seoul, Korea). Promoters were analyzed by the PLACE (Higo et al. 1999) and PlantCARE (Lescot et al. 2002) databases.

\section{Characterization of the genomic sequences}

To determine the exon-intron boundaries of $C s C C D 2$, the full-length genomic regions were isolated from $C$. sativus genomic DNA using PCR. The reaction was performed with Takara LA Taq polymerase (Takara Bio, Shiga, Japan) according to the manufacturer's instructions using the primer sets detailed in Table 1. The PCR condition was: $94^{\circ} \mathrm{C}$ for $1 \mathrm{~min}$; 30 cycles of $98^{\circ} \mathrm{C}$ for $15 \mathrm{~s}, 68^{\circ} \mathrm{C}$ for $10 \mathrm{~min}$; and $72{ }^{\circ} \mathrm{C}$ for $10 \mathrm{~min}$. The amplified PCR fragments were subcloned into pGEM-T vector (Promega Corporation, Madison, WI, USA) and sequenced using an automated DNA sequencer (ABI PRISM 3730xl, Perkin Elmer) from Macrogen Inc. (Seoul, Korea).

\section{Phylogenetic analysis}

The amino acid sequences of the selected proteins were aligned using the BLOSUM62 matrix with the ClustalW (http://www.clustal.org) algorithm-based AlignX module from MEGA Version 6.0 (http://www.megasoftware.net/ mega.html). The alignments were executed by MEGA Version 6.0 to generate a Neighbour Joining Tree with bootstrapping (5000 replicates) analysis and handling gaps with pairwise deletion.

\section{Isolation of $\mathrm{CsCCD2}$ cDNAs and analysis of protein sequences}

Total RNA and mRNA were isolated from saffron stigma at different developmental stages by using AmbionPolyAtrack (Ambion, Inc.). First-strand cDNAs were synthesized using the SMARTer ${ }^{\mathrm{TM}}$ RACE cDNA Amplification Kit (Clontech, Palo Alto, CA) and oligo dTprimers (Promega, Madison, WI). These cDNAs were used as templates for RACE- $5^{\prime}$ PCR and for $\mathrm{CsCCD} 2$ cDNA cloning using specific oligonucleotides (Table 1). The amplified PCR products were cloned into pGEM-T (Promega Corporation, Madison, WI, USA) and transformed into E. coli strain JM109. The clones isolated were sequenced as described before. 
Table 1 Primer sequences used for $C s C C D 2$ analysis

\begin{tabular}{|c|c|c|}
\hline Used for & & $5^{\prime} \rightarrow 3^{\prime}$ \\
\hline \multirow[t]{4}{*}{ RACE-5' and $3^{\prime}$ reactions } & F-1 & TGAGTTGGGACCTAGAAGATATG \\
\hline & F-2 & TCTGAGGTCAATGTCATCGATG \\
\hline & $\mathrm{R}-1$ & CCACTTCCACTGGTTGGAAATAC \\
\hline & $\mathrm{R}-2$ & CAGGTCCATGAAGATGGCATAG \\
\hline \multirow[t]{3}{*}{ cDNA amplification } & ATG1-F & CTTGACATGGAATCTCCTACTAC \\
\hline & ATG2-F & GTATCAATGGCAAATAAGGAG \\
\hline & $\mathrm{R}$ & TGTCTCTGCTTGGTGCTTCTGA \\
\hline \multirow[t]{6}{*}{ Promoter isolation and analysis } & Rp1 & GTAGCGGCCCAAATTTACGTGGA \\
\hline & $\mathrm{Rp} 2$ & TGGAAGGAAGATGGAGGAGCTCT \\
\hline & Rp3 & TGTGGTGTACAAACACCTGCATCC \\
\hline & $\mathrm{Rp} 4$ & TTACACGTTAGGCAAGATCGTCCA \\
\hline & Rp5 & CATTTCGGTGGCCCTGTTCGT \\
\hline & $\mathrm{Fp}$ & AGGTGATCATAGGTACTCCCTA \\
\hline \multirow[t]{22}{*}{ gDNA amplification and analysis } & $\mathrm{F}$ & TCTTGACATGGAATCTCCTACTACT \\
\hline & F0 & CAGTAGTATCAATGGCAAATAAGGAG \\
\hline & $\mathrm{F} 1$ & CGTCGCAGTGGACTTACTCGA \\
\hline & $\mathrm{F} 2$ & AACCCCAAGTTTGCTCCCGTC \\
\hline & $\mathrm{F} 2 \mathrm{~b}$ & CGTCACGGTTTAAACAAGAAG \\
\hline & $\mathrm{F} 3$ & ATACTAGTACTTCGAACATTGA \\
\hline & $\mathrm{F} 4$ & TGCCAACCTGGCATCAAATCT \\
\hline & F5 & TGATGAGGATGACGGTTACTTGA \\
\hline & F1-gw-3' & TCTGAGGTCAATGTCATCGATGCA \\
\hline & $\mathrm{F} 2-\mathrm{gw}-3^{\prime}$ & CAGAACCTGTGGCTGTTGTGGAAC \\
\hline & $\mathrm{FH}$ & ATGCTTGAATGGAGTGTTTCTGA \\
\hline & $\mathrm{F}(\mathrm{E}+\mathrm{I} 4)$ & CGATCCGTTAACTGGTAATTCCT \\
\hline & $\mathrm{R}(\mathrm{E}+\mathrm{I} 1)$ & ATCTGCAGGTCGAGTATAGGAGA \\
\hline & $\mathrm{R} 1$ & TTGGGGTTAGGGCCAACTCTC \\
\hline & $\mathrm{R} 2$ & TAAGCAATCCTCTTAGATCTCCA \\
\hline & $\mathrm{R} 3$ & GGAGGCGAGAGGGAATATCCA \\
\hline & $\mathrm{R} 4$ & TGTCATGTCTCTGCTTGGTGCT \\
\hline & $\mathrm{R} 5$ & TGGAAGCAACCGATACGAGCT \\
\hline & R6 & TGCATCGATGACATTGACCTCA \\
\hline & R7 & TCTCCAATCTGCAGGTCGAGTA \\
\hline & $\mathrm{R} 8$ & CCATCTTTAATACGCAATCCATGA \\
\hline & RH & ATCAGGACTCTCAAGGCGACA \\
\hline \multirow[t]{2}{*}{ For PET28 cloning and activity assays } & F-Pet28 & GACGGAGCTCGAATTCTCATGGAATCTCCTACTACT \\
\hline & R-Pet28 & TCGCGGATCCGAATTCTCATGTCTCTGCTTGGTGC \\
\hline \multirow[t]{2}{*}{ cDNA amplification CancyCCD2 } & $\mathrm{R}$ & CTACGTATTCTTAGAGACTAGT \\
\hline & $\mathrm{F}$ & TCTGACAGACCATTGTAAACGGA \\
\hline \multirow[t]{2}{*}{ cDNA amplification $\mathrm{CcaCCD} 2$} & $\mathrm{R}$ & AGTCGAAGCCCCGTTACTATCT \\
\hline & $\mathrm{F}$ & GACATGGAATCTCCTACTACTAA \\
\hline
\end{tabular}

All the CCD proteins were modelled using the Phyre2 server (http://www.sbg.bio.ic.ac.uk/phyre2/) (Kelley et al. 2015). For comparative modelling CsCCD2 proteins were aligned with the enzyme VP14, the crystal structure of which has been resolved (Messing et al. 2010).

\section{Activity assays in $E$. coli}

The full-lengths of $C s C C D 2-t$ and $C s C C D 2$ cDNAs were cloned into the EcoRI site of the expression vector pET28 (Invitrogen, Carlsbad, California, USA) by means of In- 
Fusion cloning technology (Clonthec, Mountain View, California, USA) and using gene-specific primers (Table 1). The recombinant clones were transformed in E. coli Origami strain (Novagen, Darmstadt, Germany) engineered with a plasmid for the production of zeaxanthin (Cunningham and Gantt 1998). Transformed cells were cultured overnight at $37{ }^{\circ} \mathrm{C}$ in $3 \mathrm{ml} \mathrm{LB}$ medium supplemented with kanamycin $\left(50 \mu \mathrm{g} \mathrm{ml}^{-1}\right)$ and chloramphenicol $\left(60 \mu \mathrm{g} \mathrm{ml}^{-1}\right)$. The cultured cells were transferred to $50 \mathrm{ml}$ LB medium supplemented with kanamycin $\left(25 \mu \mathrm{g} \mathrm{ml}^{-1}\right)$ and chloramphenicol $\left(30 \mu \mathrm{g} \mathrm{ml}^{-1}\right)$ and further cultured at $37{ }^{\circ} \mathrm{C}$ until an OD600 of 0.8 was reached. Cells were then induced with $0.5 \mathrm{mM}$ IPTG and grew overnight at $20{ }^{\circ} \mathrm{C}$. Cells harvest and pigment extractions and HPLC conditions were performed as previously described (Ahrazem et al. 2016).

\section{Expression analysis}

Total RNA was extracted as described above, and genespecific primers for real-time PCR are presented in Table 1. Transcript levels of CsCCD2 were normalized with that of RPS18 (Rubio-Moraga et al. 2014a), and each RNA sample was assayed in triplicate. The cycling parameters of qPCR consisted in an initial denaturation at $94{ }^{\circ} \mathrm{C}$ for $5 \mathrm{~min} ; 40$ cycles at $94{ }^{\circ} \mathrm{C}$ for $20 \mathrm{~s} 58{ }^{\circ} \mathrm{C}$ for $20 \mathrm{~s}$ and $72{ }^{\circ} \mathrm{C}$ for $20 \mathrm{~s}$; and a final extension at $72{ }^{\circ} \mathrm{C}$ for $5 \mathrm{~min}$. Assays were conducted in a StepOne ${ }^{\mathrm{TM}}$ Thermal Cycler (Applied Biosystems, Foster City, California, USA) and analyzed using StepOne software v2.0 (Applied Biosystems, Foster City, California, USA). DNA melt curves were created for each primer combination to confirm the presence of a single product.

\section{Transcript processing}

We used transcript profiling analysis to investigate splicing as a key posttranscriptional RNA maturation step in CsCCD2. For that purpose we used RNA purified from stigmas at three different stages of development (white, yellow and orange). Total RNA was extracted with Trizol (Invitrogen Life Technologies Foster City, CA, USA) and treated with DNase RNase-Free Set (Qiagen, Valencia, CA, USA), according to the manufacturer's instructions. We extracted RNA from a pool of ten independent biological replicates dissected from $C$. sativus buds. The concentration of RNA was measured in a NanoDrop ND1000 spectrophotometer (NanoDrop Technologies, Wilmington, DE). A total of $5 \mu \mathrm{g}$ of RNA from were sent to Macrogen Inc. (South Korea) for sequencing using the Genome AnalyzerIIx platform (Illumina Inc.) according to Illumina's protocols. The cDNA libraries were dissipated onto an Illumina single-end flow cell formed by eight lanes using the Illumina Cluster Station (Illumina Inc.). One lane was used per sample of white, yellow and orange stages. The $101 \mathrm{bp}$ reads obtained were collected using the Illumina GA II and sequencing-by-synthesis technology. The relative abundance of the transcripts was measured with the Cufflink software. This software measures the transcripts abundance as RPKM (Reads PerKilobase of exon model per Million mapped reads). These sequences were used to search for $C s C C D 2$ related sequences.

\section{Extraction and analysis of crocins by HPLC-DAD}

Sample processing and analysis was done as previously described (Moraga et al. 2009) with modifications. Stigmas were ground in liquid nitrogen with a mixer mill MM400 (Retsch GmbH, Haan, Germany) in a $1.5 \mathrm{ml}$ Eppendorf tube, and extracted with $1 \mathrm{ml}$ Tris- $\mathrm{HCl}(50 \mathrm{mM}, \mathrm{pH} 7.5)$ (containing $1 \mathrm{M} \mathrm{NaCl}$ ), and incubated on ice for $10 \mathrm{~min}$ followed by centrifugation at $3000 \mathrm{~g}$ for $10 \mathrm{~min}$ at $4{ }^{\circ} \mathrm{C}$. The supernatant was concentrated using a Speed Vac and the dried residues were stored at $-80{ }^{\circ} \mathrm{C}$ until analysis by HPLC. All assays were performed in triplicate. The HPLC method used for the analysis and detection of crocins have been previously described (Castillo et al. 2005; Rubio Moraga et al. 2013).

\section{Results}

\section{Exon-intron structure of CsCCD2}

We determined the exon-intron boundaries, exon and intron sizes, and intron placement of $C s C C D 2$ genes on the genome of $C$. sativus by sequence alignment of $C s C C D 2$ cDNA with the isolated gDNA sequences. Three different CsCCD2 genes were amplified from the genomic DNA of saffron and its structure determined by comparison with the CsCCD 2 cDNA clones (Supplemental Fig. S1, Fig. 1). The longest gene contained nine introns and ten exons and was named as $C s C C D 2 a$, followed in size by a gene with nine exons and eight introns, named as $C s C C D 2 b$. The third $C s C C D 2$ gene identified was identified as a truncated gene without introns, which lacks exon 8 and was named CsCCD2-t (Fig. 1). This gene encodes a protein of 480 amino acids that shows the absence of an important region for CCDs activity (Fig. 2a, b). Although the overall amino acid sequence identity among the CCDs enzymes of the different families is variable, there are consensus regions of absolute sequence conservation including the four fully conserved, iron-containing His residues. Three of these His residues hydrogen bond to a set of three conserved Glu residues (Sui et al. 2013) (Fig. 2a), which form the second coordination sphere with the ferrous ion. Although all the 
Genomic structure of CsCCD2

strand

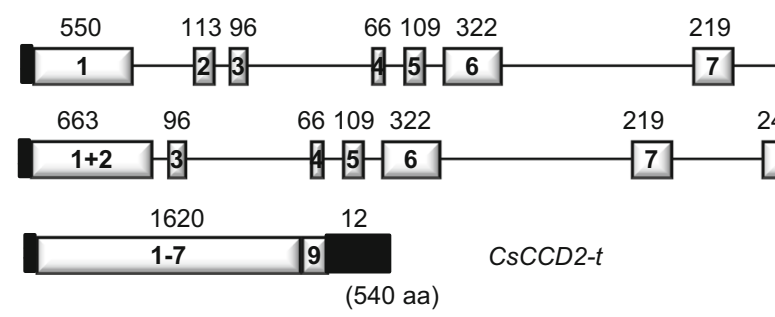

Fig. 1 Analysis of the exon-intron structures of $\mathrm{CsCCD} 2$ genes. Schematic diagram of the exon-intron structures of $C s C C D 2$ genes. Gray and black boxes indicate exons and untranslated regions

His residues are present in the CsCCD2-t protein, two Glu residues are missing in the protein (Fig. 2a). Mutagenesis studies on these residues indicate that are absolutely required for CCD catalytic function (Poliakov et al. 2005; Redmond et al. 2005; Takahashi et al. 2005). CCDs fold as a seven-blade $\beta$-propeller motif with several $\alpha$-helical inserts that form an $\alpha$-helical domain on top of the $\beta$-propeller (Kloer and Schulz 2006) that houses the active site. The iron ion cofactor is located close to the top face on the propeller axis and is coordinated by four conserved His residues and three second shell Glu residues. Each blade of the $\beta$-propeller contributes a single residue to the iron coordination system. This structure is maintained in CsCCD2, but in CsCCD2-t the $\beta$-propeller lacks blade 6 and creates a more open structure, resulting in an inappropriate "sealing" of the propeller structure (Fig. 2b). In order to determine whether CsCCD2-t was active or not, we tested its activity by expressing CsCCD2-t in E. coli strains engineered to accumulate zeaxanthin. When expression of CsCCD2-t was induced in the bacterial cells, accumulation of zeaxanthin was not affected and we were unable to identify any cleavage product by HPLC analysis compared with the activity of the full CsCCD2 enzyme (Supplemental Fig. S2).

\section{The CsCCD2 intron-structure showed similarities with the genomic-structure of CCD1genes}

The CCD2 enzymes are closely related to the CCD1 enzymes (Supplemental Fig. S3). Since the absence of other $C C D 2$ genomic sequences in the GenBank database, to further study the genomic structure of $C s C C D 2$, the genomic clones were compared by Clustal with the $C C D 1$ genes from other plant species and were selected the ones with the highest identity score at the nucleotide level (Phoenix dactylifera, PdCCD1 $79 \%$; Musa acumuniata, MaCCD1 $77 \%$; Elais guineensis, EgCCD1 $79 \%$ ) for intron/exon structure comparison (Fig. 3a, b). A distinct pattern of intron sizes emerged, and introns were observed
(UTRs), respectively. Introns are indicated by lines. The size of each exon is indicated over the exon boxes in base pairs and the size of the protein products in presented on the left of each gene in parenthesis

in a total of 13 positions in the coding region. Introns were numbered according to placement starting with intron 1 closest to the start codon, and in all the observed introns, placement was conserved (Fig. 3a, b). In CsCCD2a, introns 1, 2, 8 and 10 were absent (Fig. 3a) and in $C s C C D 2 b$ also intron 3 was missing. Intron sizes were compared among the selected $C C D 1$ and the CsCCD2 sequences (Supplemental Table S1), and the unique relative conserved intron regarding size was intron 7. However, sequence comparison among the intron sequences did not revealed any identity and/or significant similarity with any coding or non-coding sequence.

The $5^{\prime}$ and $3^{\prime}$-splice sites sequences for the intronic CsCCD2 sequences were compared with the consensus sequences of the $C C D 1$ genes from the monocot species used for intron position analysis (Fig. 3, Supplemental Fig. S3). The obtained consensus sequences (Table 2) were compared with the consensus sequences in plants (A/C)AGIGU(A/G)AGU and the UGCAGIG, at the donor and acceptor splice sites, respectively. The degree of conservation was high for both splice sites. By contrast, in the CsCCD2 sequence the $5^{\prime}$-splice sites sequences were more conserved than the $3^{\prime}$-splice sites (Table 2).

Comparison of the intron/exon structure of these sequences with other monocot and dicot CCDI genomic sequences (Supplemental Fig. S3) allowed the verification of a consensus position for each intron on the amino acid sequence (Fig. 3b), which were also present in CsCCD2 (Fig. 3a). Interestingly, the introns appear in the loops linking elements of the secondary structure (Fig. 3b) rather than in either the alpha-helical or beta-sheet segments. Such intron pattern often appeared to correlate with junctions between domains or modules of protein structure as if the gene had been assembled at an early time from an exon-sized protogene precursor (de Souza et al. 1996). Further, the analysis of the positions of the intronic sequences in the $\mathrm{CsCCD} 2$ sequence showed that certain introns delineate the structural elements of the CsCCD2 enzyme tertiary structure (Fig. 3c). Intronic sequences 1 
Fig. 2 Amino acid sequences and structural comparisons of CsCCD2 and CsCCD2-t.

a Amino acid alignment showing the conserved histidine residues highlighted with yellow shading and in grey shading the key amino acid residues necessary for CCDs catalytic activity. b Tridimensional models of CsCCD2-t $(a, c)$ and CsCCD2 $(b, d)$, with $\beta$-strands shown in cyan, $\alpha$-helices in magenta, and loops in black
(A)

CsCCD2
CsCCD2-t
CsCCD2
CsCCD2-t
CsCCD2
CsCCD2-t
CsCCD2
CsCCD2-t
CsCCD2
CsCCD2-t
CsCCD2
CsCCD2-t
CsCCD2
CsCCD2-t
CsCCD2
CsCCD2-t
CsCCD2
CsCCD2-t
CsCCD2
CsCCD2-t
CsCCD2
CsCCD2-t

MESPTTKLPAPLIMLSSSPLLLPSPYKSSSIFLPRKFGPLPPNYYYNCCHPKSRPISVVS MESPTTKLPAPLLMLSSSPLLLPSPYKSSSIFLPRKFGPLPPNYYYNCCHPKSRPISVVS

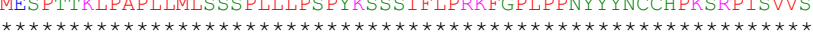

MANKEEAEKRKKKPKPLLKVLITKVDPKPRKGMASVAVDLLEKAFVYLLYGNSAADRS--S MANKEEAEKRKKKPKPLKVLITKVDPKPRKGMASVAVDLIEKAFVYLISGNSAADRSSSS

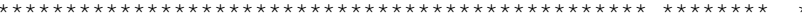

GRRRRKEHYYLSGNYAPVGHETPPSDHLPVHGSLPECLNGVELRVGPNPKFAPVAGYNWV GRRRRKEHYYLSGNYAPVGHETP SD DHLPIHGSLPECLNGVFLRVGPNPKFAPVAGYNWV

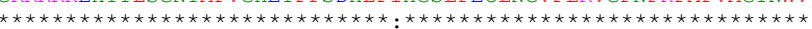

DGDGMIHGLRIKDGKATYLSRYIKTSRFKQEEYFGRAKFMKI GDLRGLLGFFTILILVLR

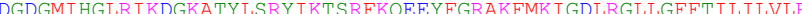

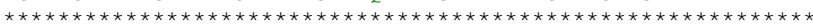

TTLKVIDISYGRGTGNTALVYHNGLLLALSEEDKPYVVKVLEDGDLQTLGILDYDKKLSH TTLKVTDISYGRGTGNTALVYHNGLLIALSEEDKPYVVKVLEDGDLQTLGILDYDKKLSH

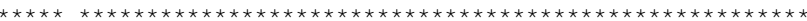

PETAHPKIDPLTDEMETFGYSLSPPYLTYRVISKDGVMQDPVQISITSPTIMHDFAITEN PFTAHPKIDPLTDEMFTFGYSISPPYLTYRVISKDGVMQDPVQISITSPTIMHDFAITEN

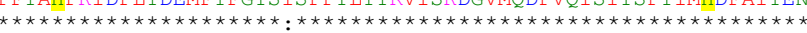

YAIFMDLPLYFQPEEMVKGKFVSSFHPTKRARIGVLPRYAEDEHPIRWEDLPSCEMTHNA YAIFMDLPLYFQPEEMVKGKFVSSFHPTKRARIGVLPRYAKDEHPIRWEDLPSCFMTHNA

NAWEENDEVVLFTCRLESPDLDMLSGPAEEEIGNSKSELYEMRFNLKTGITSQKQLSVPS NAWEENDEVVLFTCRLESPDLDMLSGPAEEEIGNSKSELYEMRFNLKTGITSOKOLSVPS NAWEENDEV LFICRLESP DLDMLSGPAEEEIGNSRSELYMRRNLKIGIISQRQLSVPS

VDFPRINQSYTGRKQQYVYCTLGNTKIKGIVKFDLQIEPEAGK̈TMLEVGGNVQGIFELGP VDFPRINQSYTGRK

RRYGSEAIFVPCQPGIKSDEDDGYLIFFVVHDENNGKSEVNVIDAKTMSAEPVAVVQLPSR SEVNVIDAKTMSAEPVAVVELPSR

VPYGFHALFLNEEELQKHQAET VPYGFHALFLNEEELQKHQAET
(B) (a)

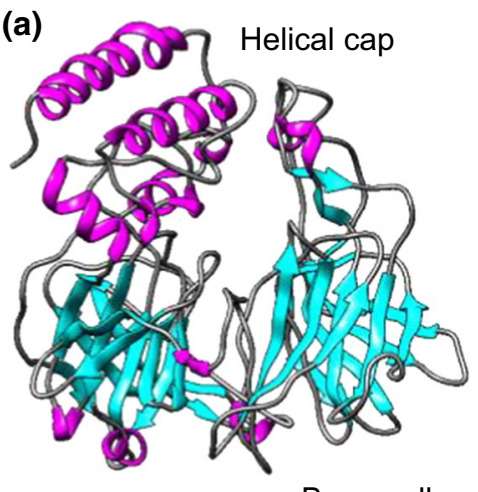

(c)

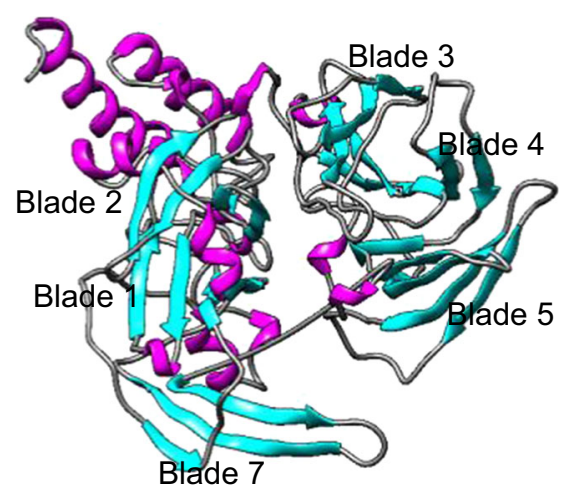

(b)

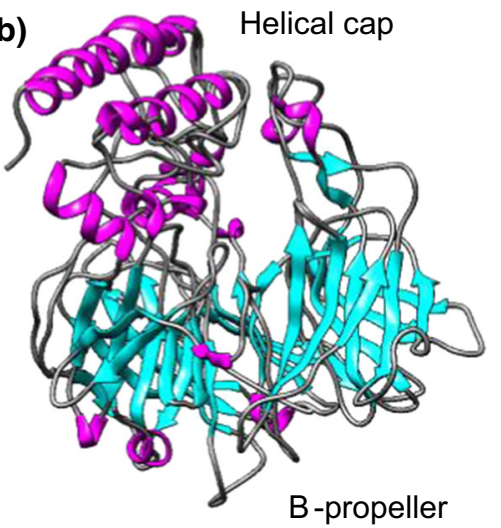

(d)

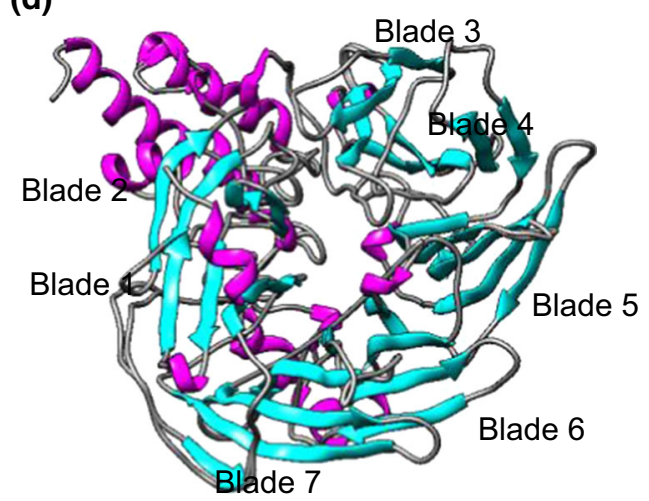


(A)
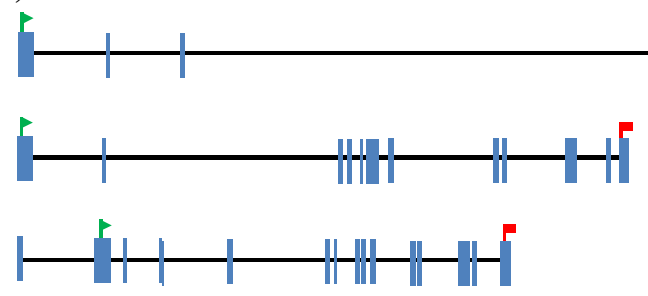

PdCCD1

MaCCD1

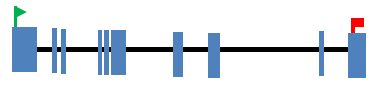

CsCCD2a $1,2,8$ and 10

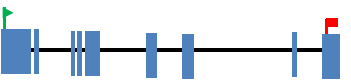

$\operatorname{CsCCD} 2 b \quad 1,2,3,8$ and 10

(B) 1 .

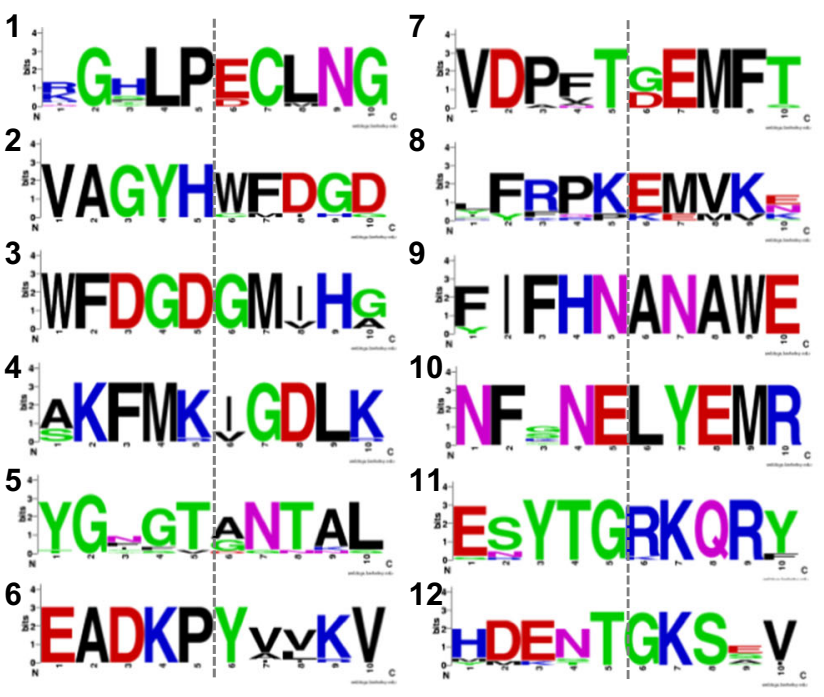

13.

FFVTEEQLé,

3- WVDGD/GMIHG

4- AKFMK/IGDLR

5 - YGRGT/GNTAL

6- EEDKP/YVVKV

7 - IDPLT/DEMFT

9- FMTHN/ANAWE

11 -QSYTG/RKQQY

12-HDENN / GKSEV

13-LFLNE / EELQK

(C)
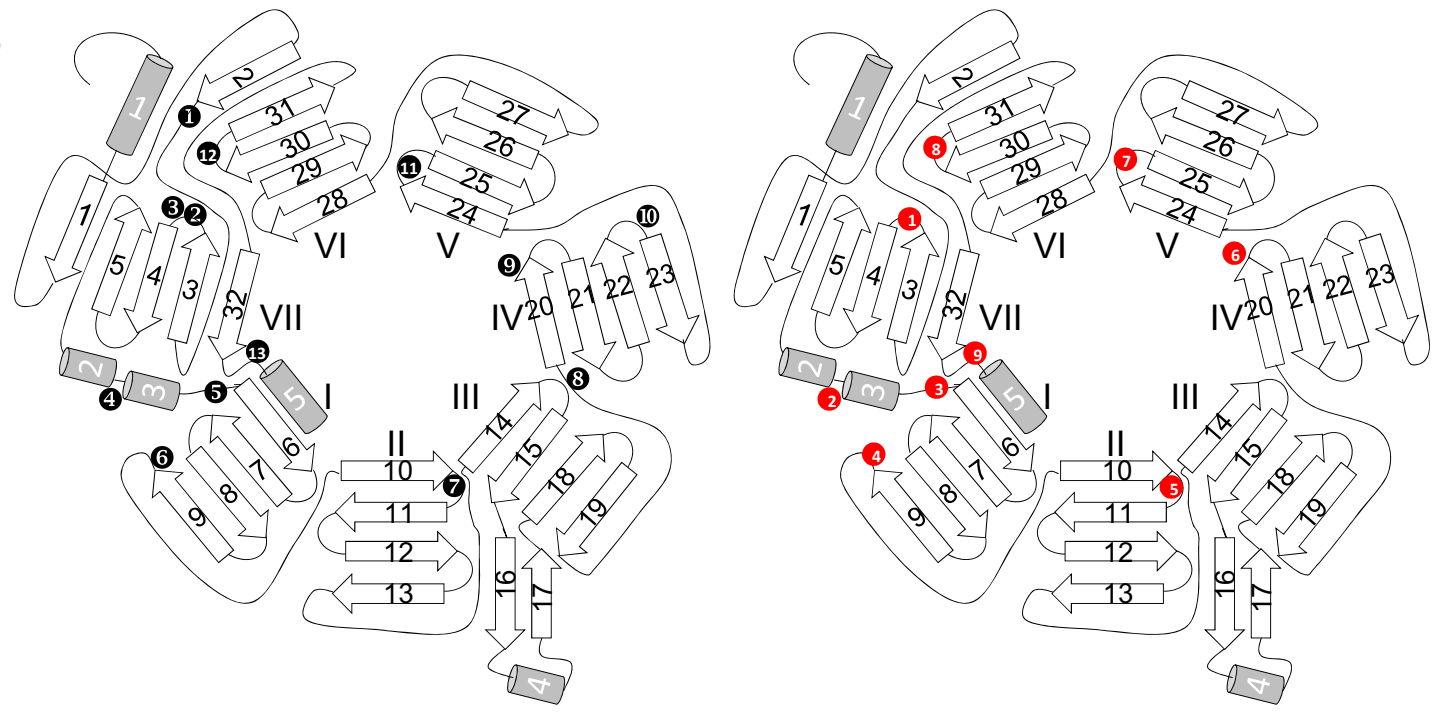
4 Fig. 3 Intron-exons properties of $C s C C D 2$ and related $C C D 1$ genes and protein structure. a Genomic structure of Elaeis guineensis CCD1, EgCCD1; Phoenix dactylifera CCD1, PdCCD1; Musa acuminata CCD1, MaCCD1 and Crocus sativus CCD2 genes, CsCCD2. The green flag and red flags indicate the start and stop codons positions, respectively. b Amino acid consensus sequences around the insertion position of the conserved introns detected among the sequences listed in Supplemental Fig. S4. The grey vertical bar denotes the place where the intron is inserted in the nucleotide sequence. Intron number is indicated by numbers. In the left, in blue shading are presented the corresponding amino acid sequences in CsCCD2. Conserved amino acids are in bold. The numbers denote the intron inserted in the nucleotide sequence. c Schematic diagram of CCDs topology showing the seven-blade $\beta$-propeller as the basic motif. The location of the splice junctions mapped on the protein sequence are shown in the left as numbers with black background for the CCD1 sequences, and on the right as numbers with red background for the introns of CsCCD2a (where number 1 correspond with intron 3 in CCD1, number 2 with intron 4, number 3 with intron 5 , number 4 with intron 6 , number 5 with intron 7 , number 6 with intron 9, number 7 with intron 11 , number 8 with intron 12 and number 9 with intron 13)

and 2 delineate the bladeVII; intronic sequences 3 and 4 delimitated blade I; intronic sequences 5 and 6 delimitated blades II and III; intronic sequences 6 and 7 delimitated blade IV; intronic sequences 7 and 8 delimitated blades $\mathrm{V}$ and VI; in the seven-blade $\beta$-propeller structure (Fig. 3c).

\section{Expression analysis of CsCCD2 in stigma tissue}

The presence of the truncated clone encoding for an inactive enzyme, prompted us to evaluate its involvement in apocarotenoid regulation in saffron. To answer the question of whether the truncated gene was expressed, reverse transcriptase-PCR assays combined with RACE-PCR experiments were performed with RNA from yellow and orange stigmas using oligonucleotides to ensure the isolation of the complete CsCCD2 cDNA (Supplemental Fig. S4). Two different populations differing in size were obtained after the amplification reactions, and the sequence of each population confirmed the expression of the truncated clone in both developmental stages. Both kind of clones showed in the $5^{\prime}$-UTR the consensus sequence $\mathrm{A}(-4)(\mathrm{A} / \mathrm{G})(-3)(\mathrm{A} / \mathrm{C})(-2) \mathrm{A}(-1) \mathrm{ATGG}(+4) \mathrm{C}(+5)(\mathrm{U} / \mathrm{G})$ (+6) for the plant genes (Nakagawa et al. 2008) and a $357 \mathrm{bp}$ at the non-coding $3^{\prime}$ region excluding the poly(A) tail which starts 29 bp downstream from a putative polyadenylation signal, AATAAT.

To determine the possible functional implications of CsCCD2-t, we investigated the presence of CsCCD2$t$ homologous in other Crocus species, one of them closely related to $C$. sativus, $C$. cartwrightianus also flowering in autumn (Castillo et al. 2005), and the other one flowering in spring, C. ancyrensis (Rubio Moraga et al. 2013). The truncated form of $C C D 2$ was isolated from the stigmas of C. ancyrensis and C. cartwrightianus (Fig. 4a), suggesting a conserved function for such isoform in all the analyzed species. The main observed differences among the isolated sequences were found in the $\mathrm{N}$-t region of the amino acid sequences (Fig. 4a). Interestingly, among the full length CsCCD2 clones isolated in the RACE-PCR experiments, three different classes were isolated, which differed in the same $5^{\prime}$ region identified as different for the CCD2 truncated clones (Fig. 4a, b, Supplementary Fig. 4), and this region is absent in the CCD1 protein from $C$. sativus (amino acid sequence 4 [UniprotID Q84KG5], in Fig. 4b). This region does not correspond to any of the positions were introns are located in the genomic sequence (Fig. 3a).
Table 2 The $5^{\prime}$ and $3^{\prime}$-splice sites sequences for the intronic CsCCD2 sequences, compared with the consensus sequences of the $C C D 1$ genes from the monocot species

\begin{tabular}{|c|c|c|c|}
\hline $\begin{array}{l}\text { Intron } \\
\text { number }\end{array}$ & $5^{\prime}(\mathrm{A} / \mathrm{C}) \mathrm{AG} \operatorname{lgu}(\mathrm{a} / \mathrm{g}) \mathrm{agu}$ & $3^{\prime}$ caglG & $\begin{array}{l}\text { Intron } \\
\text { phase }\end{array}$ \\
\hline 3 & GA-UGguaaca & ugcaGAAU & 1 \\
\hline 4 & GAAGguagau & gcagAUUG & 0 \\
\hline 5 & GACUgguaac & auucGGUA & 0 \\
\hline 6 & ĆUㅂguaagu & caagAUGU & 1 \\
\hline 7 & A믐gguaau & caacGAUG & 2 \\
\hline 9 & UAAAUgguuuc & uagcGCAA & 0 \\
\hline 11 & ACEUGgcaggu & aauuAGGA & 0 \\
\hline 12 & AUGGguacua & aguaAAAU & 1 \\
\hline 13 & UGAGagguua & uacuGAAG & 0 \\
\hline
\end{tabular}




\section{(A)}

CaCCD2-t
CsCCD2-t
CcarCCD2-t
CaCCD2-t
CsCCD2-t
CcarCCD2-t
CaCCD2-t
CsCCD2-t
CcarCCD2-t
CaCCD2-t
CsCCD2-t
CcarCCD2-t
CaCCD2-ta
CsCCD2-t
CcarCCD2-t

M-----YAPIPPLLLLSSFLL-P---PKSSMFLPRKLGYRLPKYYCRK----ER-ISV-MESPTTKLPAPLLMLSSSPLLLPSPYKSSS IFLPRKFGPLPPNYYYNCCHPKSRPISVVS MESPTTKLPAPLLMLSSSPFLLPSPYKSSS IFLPRKLGPLP PNYYYNCCHPKSRPISVVS

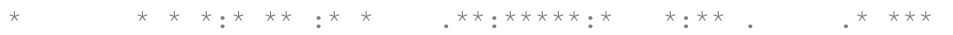

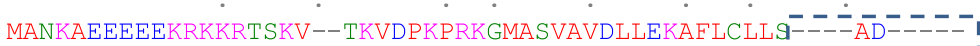
MANKEEAEKRKKKPKPLKVLITKVDPKPRKGMASVAVDLLEKAFVYLLSGNSAADRSSSS ! MTNKEGAEKRKKKPKPLKVLITKVDPKPRKGMASVAVDLLEKAFVYLLYGNSAADRSS-$* * * * * * * * * * \quad * * * * * * * * * * * * * * * * * * * * * * * *$
I $* * *$
IGRRRRKEHYYLSGNYAPVGHETPPSDHLPI HGS LPECLNGVFLRVGPNPKFAPVAGYNWV INRRRRKEHYYLSGNYAPVGHETPPSDHLPVHGSLPECLNGVFLRVGPNPKFAPVAGYNWV

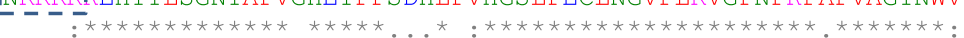
DGDGMIHGLRIKDGKPTYLSRYVKTSRFKQEEYFGRAKFMKIGDLRGLLGLITILILVLR DGDGMIHGLRIKDGKATYLSRYIKTSRFKQEEYFGRAKFMKIGDLRGLLGFFTILILVLR DGDGMIHGLRIKDGKATYLSRYIKTSRFKQEEYFGRAKFMKIGDLRGLLGFFTILILVLR $* * * * * * * * * * * * * * * \quad * * * * * *: * * * * * * * * * * * * * * * * * * * * * * * * * * *:: * * * * * * * *$ TVLKVVDLSYGRGTGNTALVYHNGLLLALSEEDKPYVVKVLEDGDLQTLGILDYDKKLSH TTLKVTDISYGRGTGNTALVYHNGLLLALSEEDKPYVVKVLEDGDLQTLGILDYDKKLSH TTLKVIDISYGRGTGNTALVYHNGLLLALSEEDKPYVVKVLEDGDLQTLGILDYDKKLSH

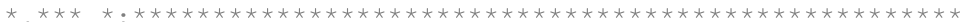
PFTAHPKIDPLTDEMFTFGYSLPPPYLTYRVISKDGVMQNPVPISITSPAIIHDFAITES PFTAHPKIDPLTDEMFTFGYSISPPYLTYRVISKDGVMQDPVQISITSPTIMHDFAITEN PFTAHPKIDPLTDEMFTFGYSLSPPYLTYRVISKDGVMQDPVQISITSPTIMHDFAITEN

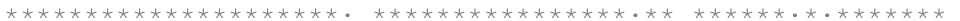
YAIFMDLPLYFRPEEMVKGKFVTSFHATKRARIGVLPRYAKDEHTIRWFDLPSCFMTHNA YAIFMDLPLYFQPEEMVKGKFVSSFHPTKRARIGVLPRYAKDEHPIRWFDLPSCFMTHNA YAIFMDLPLYFQPEEMVKGKFVSSFHPTKRARIGVLPRYAEDEHPIRWFDLPSCFMTHNA

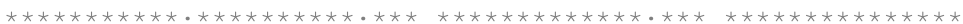
NAWEENDEVVLFTCRLESPDLEMLSGPVEEEIGNSKSELYEMRFNLKTGITSQKQLSVPS NAWEENDEVVLFTCRLESPDLDMLSGPAEEEIGNSKSELYEMRFNLKTGITSQKQLSVPS NAWEENDEVVLFTCRLESPDLDMLSGPAEEEIGNSKSELYEMRFNLKTGITSQKQLSVPS N VDEPRINQSYTGRK EVNVINAKTMSAEPVAVVELPSRVPYGFHALFLNEEELQKHQAET VDFPRINQSYTGRK EVNVIDAKTMSAEPVAVVELPSRVPYGFHALFLNEEELQKHQAET VDEPRINQSYTGRK EVNVIDAKTMSAEPVAVVELPSRVPYGFHALFLNEEELQKHQAET

(B)

\section{Nucleotide sequence}

$$
\begin{aligned}
& \text { 1-GGAAATTCTGCAGCTG------ATCGTAGTAGT-G-------GTCGTCGTCGTAAA } \\
& \text { 2-GGAAATTCTGCAGCTGCAGCTGATCGTAGTAGTAGTAGTGGTCGTCGTCGTCGTAAA } \\
& \text { 3-GGAAATTCTGCAGCTG------ATCGTAGTAGTAGTAGTGGTCGTCGTCGTCGTAAA }
\end{aligned}
$$

$$
\begin{aligned}
& \text { Amino acid sequence } \\
& \text { 1-GNSAA--DRSS---GRRRK } \\
& \text { 2-GNSAAAADRSSSSGRRRRK } \\
& \text { 3-GNSAA--DRSSSSGRRRRK } \\
& \hline \text { 4-DKS---------------K }
\end{aligned}
$$

Fig. 4 Alignment of amino acid sequences of CCD truncated proteins. a Amino acid sequences of CsCCD2 truncated (CsCCD2t) homologues detected in $C$. ancyrensis (CaCCD2-t) and $C$. cartwrightianus (CcarCCD2-t). Asterisk indicates conserved amino acid residues. The hatched box denotes the deletion observed in

\section{Promoter in silico analysis}

Genome walker analyses allowed the isolation of a promoter region for $C s C C D 2$. Using different primer combinations from the promoter and the coding sequence and performing sequence analysis on the amplified band, the
CaCCD2-t and CcarCCD2-t. b Comparison at the nucleotide and amino acid level of the different $5^{\prime}$ regions of the $C s C C D 2$ genes amplified in the RACE-PCR experiment. Number 1, 2 and 3 are all for $C s C C D 2$ variants, and number 4 for $C s C C D 1$

promoter sequence corresponded to $C s C C D 2 b$. The promoter sequence isolated was $1575 \mathrm{bp}$ long and was analysed using PLACE, RegSite Database of Plant Regulatory Elements and PlantCARE databases. Several putative regulatory elements were detected in these analyses (Table 3, Supplemental Table S2). The promoter 
showed several light-regulatory units (LRUs), cis-acting elements involved in heat stress and low temperature responsiveness (flowering in saffron is temperature-controlled), a wound response element and stress-cis-acting elements. In addition, three cis-acting elements involved circadian control were detected in the promoter region. The CAANNNNATC motif is conserved in the promoters of clock-controlled light-harvesting complex protein genes (Lhc) (Piechulla et al. 1998), the CCACA (ACCA CAAAA) motif has been found in the promoters of dawnphased genes (Covington et al. 2008) and the protein box element (PBX; ATGGGCC) confers midnight-phased expression on a luciferase reporter gene (Harmer and Kay 2005)

Light response, wounding, $\mathrm{ABA}$ responsiveness and circadian regulatory elements were also detected in other stigma-specific gene related with the carotenoid metabolism in saffron (Ahrazem et al. 2010a). In order to identify other putative common regulatory elements in both promoter sequences, we compare the $C s C C D 2 b$ promoter with the promoter of $C s L y c B 2 a$ using the Promoterwise program (McWilliam et al. 2013). Seven common sequences were identified (Table 4) that does not correspond to any of the previously identified cis-regulatory elements.

\section{CsCCD2 expression analysis for validation of identified $c i s$-acting regulatory elements involved in $\mathrm{CsCCD2}$ regulation}

The in silico analysis of the $C s C C D 2 b$ promoter showed the presence of light-regulatory units (LRUs), and cisacting elements involved in heat stress and low temperature responsiveness. Low temperature induced the expression of CsCCD2 whereas high temperature repressed its expression (Fig. 5a). Similar results were observed for the effect of light on $C s C C D 2$ expression. Light repressed $C s C C D 2$ expression and dark conditions induced $C s C C D 2$ expression in the stigma tissue (Fig. 5a). In addition, when the stigma from plants growing in dark conditions were assayed for $C s C C D 2$ expression and crocin content, CsCCD2 levels and crocin content were higher in the stigma derived from plants growing completely under dark conditions than in plants growing in normal light/dark conditions (Fig. 5b). Stigmas were also treated with $\beta$-cyclocitral (B-CC), produced in the earlier developmental stages of the stigma in the absence of light (Rubio et al. 2008), but in Arabidopsis it accumulates in leaves under high-light stress (Ramel et al. 2012). Under our conditions, $\beta$-cyclocitral induced the expression of CsCCD2 similarly to the treatment in darkness (Fig. 5a).

Table 3 Putative cis-elements identified in $C s C C D 2 b$ promoter

\begin{tabular}{|c|c|c|c|}
\hline Category & Cis-acting Element & Sequence & Position \\
\hline \multirow[t]{9}{*}{ Light } & ACE & AAAACGTTTA & $+416,+753,+638$ \\
\hline & G-Box & CACGTT & +385 \\
\hline & G-box & ACACGTGGC & $-409,-729$ \\
\hline & GATA-motif & GATAGGA & -468 \\
\hline & GTGGC-motif & CATCGTGTGGC & $-967,-1199$ \\
\hline & Sp1 & GGGCGG & -526 \\
\hline & & $\mathrm{CC}(\mathrm{G} / \mathrm{A}) \mathrm{CCC}$ & +1205 \\
\hline & I-box & CTCTTATGCT & +1081 \\
\hline & & ATGATATGA & $-276,+1142$ \\
\hline Heat-stress response & HSE & AAAAAATTTC & $+345,+608,-471$ \\
\hline Low-temperature response & LTR & CCGAAA & $+210,+635,-299$ \\
\hline MYB binding site involved in drought-inducibility & MBS1 & AAAAAAC & +413 \\
\hline $\mathrm{ABA}$ response & ABRE & GACACGTGGC & -968 \\
\hline Wound-response & WUN & AAATTTCCT & +611 \\
\hline Core promoter element & TATA-box & ATATAT & -109 \\
\hline Common cis-acting element in promoter and enhancer regions & CAAT-box & CAAT & $-97,-248,-662,-918,-1092$ \\
\hline Stress signal integration & ERRE & AGCCGCC & +837 \\
\hline \multirow[t]{3}{*}{ Circadian regulation } & Circadian & CAANNNNATC & -512 \\
\hline & CCACA & ACCACAAAA & +857 \\
\hline & PBX & ATGGGCC & +1362 \\
\hline
\end{tabular}


Table 4 Commom sequences identified in $C s C C D 2 b$ and CstLcyB2a promoters using PromoterWise

\begin{tabular}{lll}
\hline Sequence & CsCCD2 & CstLcyB2a \\
\hline GTTAGGACTT & GTTAGGACTT(-1542) & GTTAGGACTT(44) \\
TGTCACATATTTTTAT & TGTCACATATATTTTAT(-137) & TGTCACATTTTTAT(301) \\
GGTTAAAAAAATT & GGTTAAAAAAAATT $(-948)$ & GGTTAAAAATAATT(319) \\
ATTTTTTTAACCGA & ATTTTTTTTAACCCGA(936) & ATTTTTTATAAACCGA(370) \\
AAAAATAAAAAAA & AAAAATAAAAAAA $(-469)$ & AAAAATAAAAAAA(524) \\
CCAAA TTTATACGT & CCAAACTTTATACGT $(-1232)$ & CCAAAATTTATACGT(558) \\
AAT TTTAACCCA & AATGTTTAACCCA $(-1038)$ & AATTTTAACCCA(723) \\
\hline
\end{tabular}

Due to the involvement of light and temperature in the control of $C s C C D 2$ expression, we performed quantitative RT-PCR experiments to identify any patterns of $C s C C D 2$ transcript fluctuation over a normal ambient daily light/darkness period. CsCCD2 expression displayed a clear rhythmic nature. The level of $C s C C D 2$ expression increased during the night period, and maximum $C s C C D 2$ transcript accumulation was detected at approximately at 2:00 a.m.; the level then declined an average of 1.7-fold during the light period (1:00 p.m.) (Fig. 5c). Similarly, we found such rhythmic expression pattern for the transcripts of two saffron genes encoding proteins involved in carotenoid biosynthesis in the stigma tissue of saffron; the $\beta$ ring carotene hydroxylase, $\mathrm{CsBCH}$ gene (Castillo et al. $2005)$ and the lycopene- $\beta$-cyclase gene, CstLcyB $2 a$ (Ahrazem et al. 2010a) (Fig. 5c). CstLcyB2a expression levels reached its higher level during the night period (2:00 p.m.) and the level declined at least twofold during the light period (1:00 p.m.), while $C s B C H 1$ gene expression showed a 1.4-fold fluctuation between (2:00 a.m. and 1:00 p.m.).

\section{Identification of alternative splicing events in $\mathrm{CsCCD2}$}

Post-transcriptional control of mRNA is a key regulatory mechanism that modulates plant responses to several environmental changes, including temperature and light fluctuations (Reddy et al. 2013). Using different primers combinations we observed the presence of longer and shorter products of $C s C C D 2$ compared with the expected size product in RT-PCR experiments using cDNA from yellow and orange stigmas (Supplemental Fig. S5). To explore the extent and conservation of alternative splicing (AS), if any, in $C s C C D 2$ genes, we evaluated in three saffron RNA-seq datasets (Supplemental Table S3) obtained from white, yellow and orange stigma (Fig. 6a) the presence of alternative splicing or intron retention in $C s C C D 2$ transcripts. In addition, the obtained data allowed us to get strand orientation information, which was used to identify the $\mathrm{CsCCD} 2$ genomic sequences and their respective transcripts, as they were in different orientations. Transcripts with introns were identified in all the three datasets, but in comparison with $C s C C D 2$ transcripts without introns, they were more predominant in white $(68.7 \%)$ and yellow stages $(30.2 \%)$ and than in the orange stage $(15.8 \%$ ) (Fig. 6b). Interestingly, intron variants follow a different behaviour depending on the gene from which they came from. Whereas intron 2, 3 and 4 were predominantly retained in $C s C C D 2 b$, introns 6,8 and 9 were predominantly retained in $C s C C D 2 a$. Further, we analysed the recent published transcriptomes from several tissues from $C$. sativus (Jain et al. 2016) in order to determine the presence of intron retention in $C s C C D 2$ in those tissues were saffron apocarotenoids do not accumulated (Rubio-Moraga et al. 2010). In corm and stamens $100 \%$ of the $C s C C D 2$ sequences contained introns, in leaves $91 \%$ of the $C s C C D 2$ sequences contained introns, and in tepals $87 \%$ of the detected $C s C C D 2$ sequences contained introns. Intronic sequences 2 and 3 were predominantly retained followed by intron 6 and 4 .

Analyses of the putative protein sequences derived from the different intron retention events showed that intron 9 retention in $C s C C D 2 a$ resulted in a protein 11 amino acids longer, where none of the key conserved residues for the catalytic activity of CCD proteins were affected (Supplemental Fig. S6). By contrast, the retention of all the other introns resulted in proteins depleted in structural motives from the seven-blade $\beta$-propeller; the number of blades is getting reduced as the intron retained is closer to the start codon (Supplemental Fig. S7).

\section{Discussion}

The saffron $C C D 2$ gene, $C s C C D 2$, has previously been shown to encode the enzyme responsible for crocetin production in saffron (Frusciante et al. 2014). CsCCD2 expression is developmentally regulated and the enzyme localized in chromoplasts (Ahrazem et al. 2016), where crocetin is produced. Thereafter crocetin is glucosylated to crocins (Moraga et al. 2004), which are transported to the vacuoles, where accumulate (Grilli-Caiola and Canini 2004). This pathway remains largely uncharacterized, and 


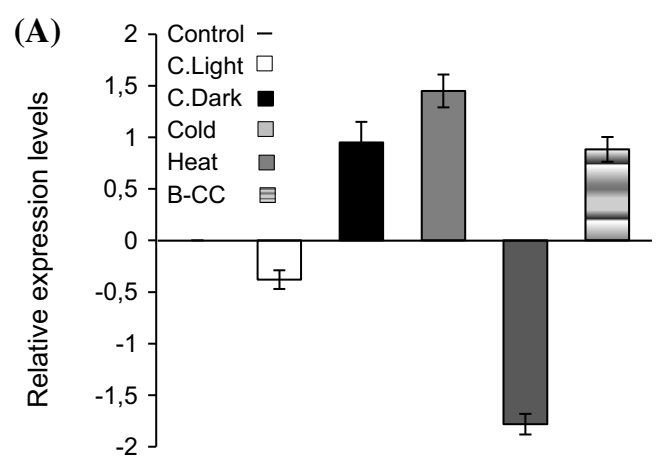

(B)
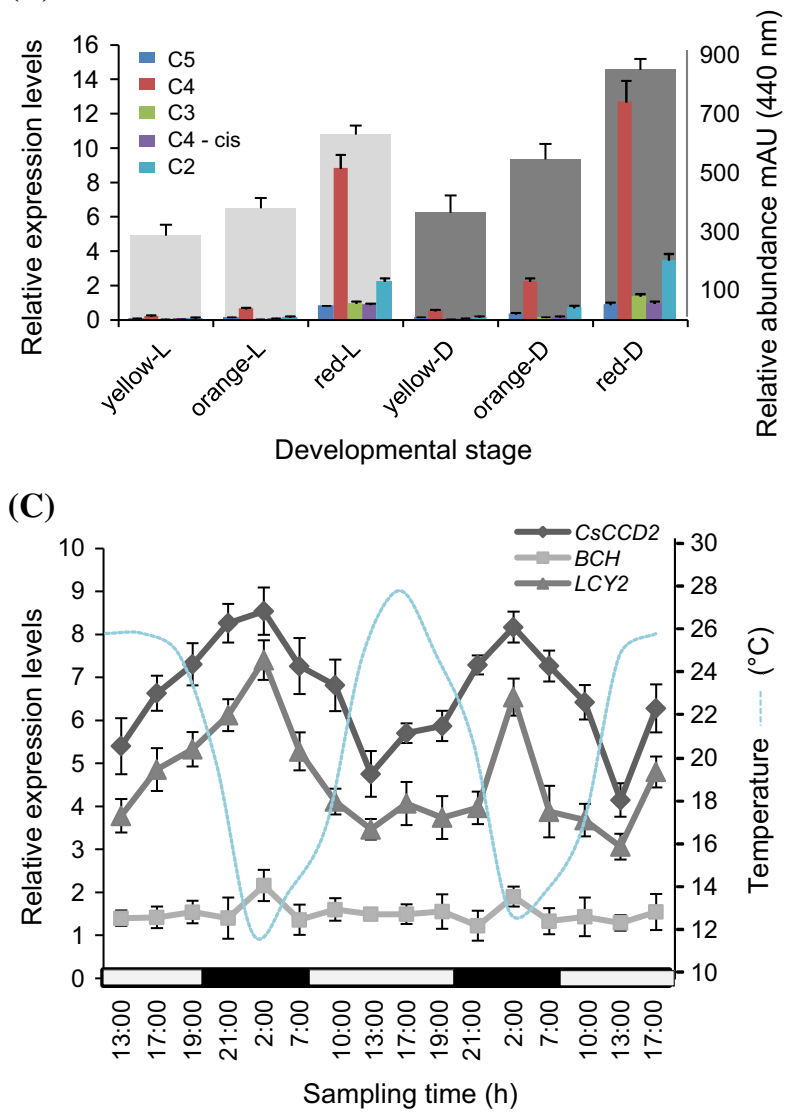

Fig. 5 Validation of $C s C C D 2$ expression based on the elements identified by in silico promoter analysis by qRT-PCR. a Expression levels of $C s C C D 2$ under different light and temperature conditions. Represented values were obtained after subtracting the control value. c Light stands for continuous light and C. Dark stands for continuous dark. b Expression levels of $C s C C D 2$ in stigmas at different developmental stages (yellow, orange, and red) from plants growing in continuous dark (yellow-D, orange-D and red-D) or normal (light/ dark) conditions (yellow- $L$, orange- $L$ and red-L) are plotted on the left $y$-axe. Crocins levels (on the right axe) for each treatment and developmental stage are also indicated. C5, trans-crocin with 5 glucose molecules; $\mathrm{C} 4$, trans-crocin with 4 glucose molecules; C4cis, cis-crocin with 4 glucose molecules; C3, trans-crocin with 3 glucose molecules; $\mathrm{C} 2$, trans-crocin with 2 glucose molecules crocins abundance on. $\mathbf{c}$ Expression data of $C s C C D 2, C s B C H 2$ and $C s L y c B 2 a$ from plants growing in field. Expression levels are plotted on the left $y$-axe, and temperature on the right. White box on $x$-axe, light interval; black box, dark interval major questions include the mechanisms that regulate CsCCD2 expression and activity. In this study, we extended the structural and functional analysis on CsCCD2 to shed light on the regulation of this enzyme during the development of the stigma in saffron and its relation with other CCD enzymes. We found that the production of crocetin from the $7,8\left(7^{\prime}, 8^{\prime}\right)$ cleavage of zeaxanthin, results from a evolutionary specialization from a CCD ancestor of the CCD1 sub-family. Further, to investigate the control of CsCCD2 gene expression during the development of the stigma of saffron, we cloned a promoter fragment upstream of $C s C C D 2$ directly from $C$. sativus genomic DNA by PCR-genome walker. Several types of cis-regulatory elements were identified and some were found to be shared with the promoter region of the chromoplast-specific lycopene cyclase encoding gene $C s L y c B 2 a$ (Ahrazem et al. 2010a). The identification of light and temperature-responsive elements in both promoters has allowed us to determine the coordinated regulation of $C s L y c B 2 a$ and CsCCD2 in saffron stigma.

\section{Intron loss in the $\mathrm{CCD} 2$ sequences}

The carotenoid cleavage genes from animals and plants are characterized by the presence of several introns in their genomic sequences, with the exception of the $C C D 4$ family in plants, with a reduced intron number (Ahrazem et al. 2010b), suggesting the presence of intronic sequences in the ancestor of the carotenoid cleavage family (Ahrazem et al. 2010b). Phylogenetic relationships and the conservation of genomic organization throughout the CCD1 and CCD2 subfamilies provides a compelling argument for reconstructing the evolutionary history of $\mathrm{CCD} 2$ on the basis of a proposed pattern of intron loss from the common ancestral CCD from which CCD2 and CCD1 evolved. The $C C D 1$ sequences from the non-grass monocots contain 12-13 introns present in conserved positions. This intron number is also present in the genomic CCDI sequences from dicotyledonous species, suggesting the presence of at least 13 introns in the $C C D 1$ ancestor sequence. Two of the CsCCD2 sequences analyzed have lost 4 and 5 intronic sequences. Interestingly, the first two introns were missing in both $C s C C D 2$ sequences. It has been shown that some introns are involved in the regulation of spatial or temporal expression of specific genes in different plants species, particularly, in the case of genes that are known to express constitutively, such as PAT1,PhADF1,PRF1, 2 and 3; and Ubi.U4, first introns were required for their constitutive expression (Jeong et al. 2006; Mun et al. 2002; Plesse et al. 2001; Rose and Last 1997). In saffron, and in other plant species, $C C D 1$ is constitutively expressed in reproductive and vegetative tissues (Rubio et al. 2008), whereas CsCCD2 expression is restricted to reproductive tissues 
Fig. 6 Splice variants of CsCCD2 in three key developmental stages of saffron stigma. a Three developmental flower stages characterized by crocin accumulation in the stigma tissue. b Representation of the percentage of intron retention transcripts identified in the RNA-seq datasets from the stages presented in a
(A)
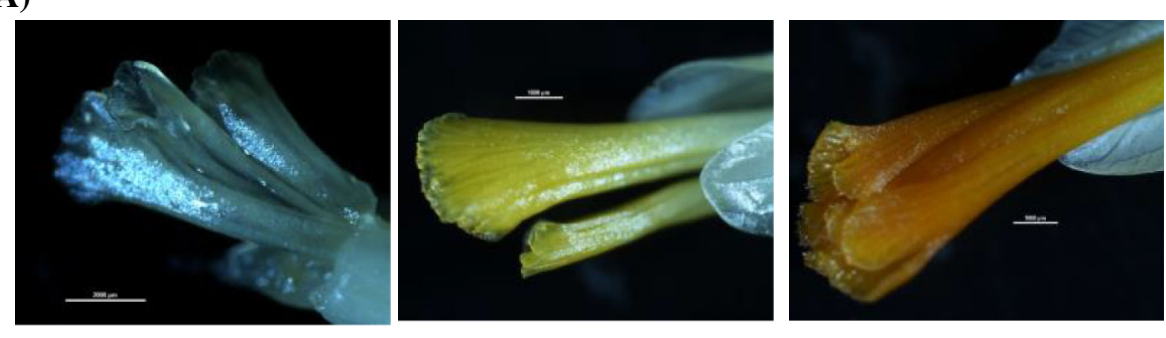

(B)
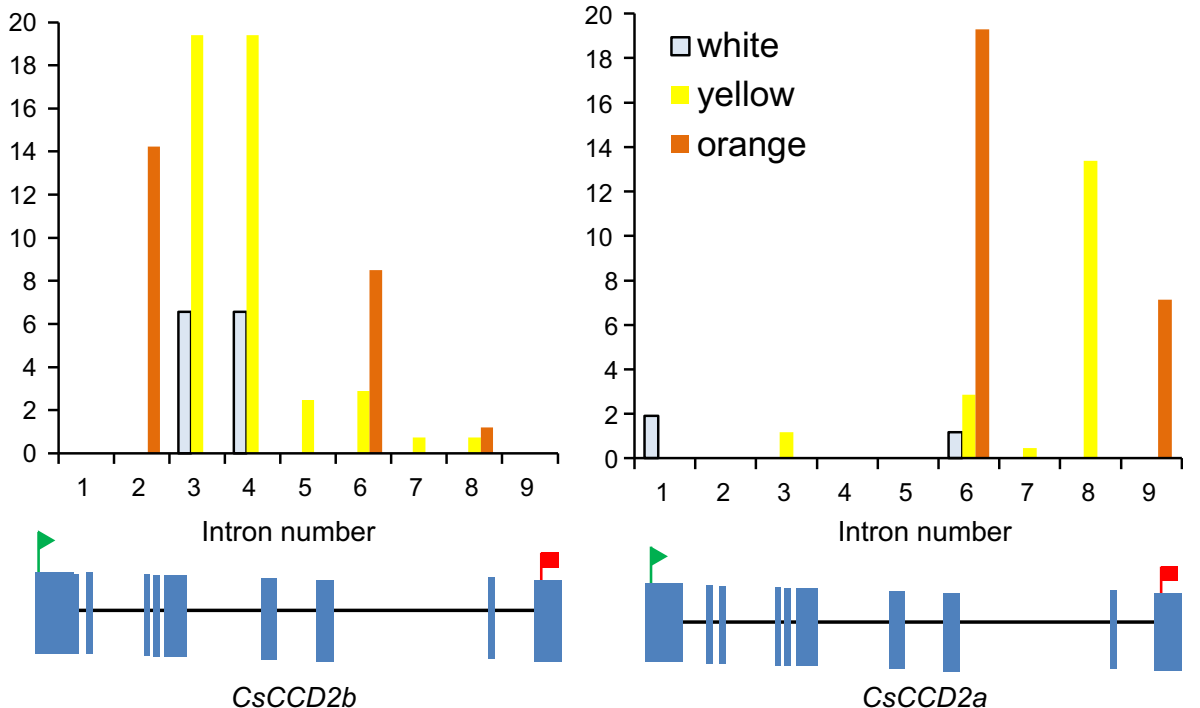

and its expression is developmentally controlled (Rubio et al. 2008). The first CCD1 intronic sequences analysed were relatively long, although the biological significance of long introns is not certain at present, long introns may serve as binding sites for various regulatory elements (Duret 2001; Marais et al. 2005). The lost of the first intronic sequences in the $C s C C D 2$ sequence might allow a restricted specialization in terms of the specific expression pattern. Such regulation can be tissue-specific, controlled by developmental cues or modulated in response to external stimuli (Reddy et al. 2013).

We identify a $C s C C D 2$ genomic sequence without introns, which also lacks one exon. This sequence, $C s C C D 2-t$, could be arisen by a retroposition event, since retroposition uses mature mRNA as the template instead of intron-containing pre-mRNA (Brosius 2003; Kaessmann et al. 2009). Interestingly, the $C s C C D 2-t$ gene is expressed in the stigmas of saffron but at lower levels than CsCCD2 (Supplemental Fig. S4), although was as well developmentally regulated and was only detected in the early developmental stages of the stigma. A CsCCD2- $t$ gene homolog was also detected in other two Crocus species that belong to different sections of the genus Crocus, section Crocus and section Nudiscapus which grouped 150 species of the genus, indicating its presence before the speciation process, and suggesting a functional role in the studied species. CsCCD2- $t$ codifies for a protein of 480 amino acids, while CsCCD2 is 622 amino acids long. The CsCCD2-t is an inactive enzyme most probably due to the absence of important residues for catalytic activity. Truncated proteins may still perform part of their function and may act as dominant-negative regulators. Indeed, several recent studies provide evidence in support of such a dominant regulatory role for truncated proteins produced by splice variants in plants (Reddy et al. 2013). The Arabidopsis CCD1 enzyme has been suggested to act as a dimer (Schwartz et al. 2001), if this is also the case for $\mathrm{CsCCD} 2$ the presence of CsCCD2-t could be part of a regulatory mechanism for $\mathrm{CsCCD} 2$ activity.

\section{Splice variants in $C s C C D 2$}

The presence of several introns allowed the detection of different splice variants for the $C s C C D 2$ genes. These mRNA isoforms may differ in the untranslated regions (UTRs) with functional implications in transcript localization, stability, or translation. It has been estimated that close to $50 \%$ of plant genes have alternative transcript 
isoforms (Filichkin et al. 2010) with retention of introns as the most frequent kind of alternative splicing (Staiger and Green 2011) and is prominent in stress-response pathways (Mastrangelo et al. 2012; Ner-Gaon et al. 2004). Recent mapping of eukaryotic transcriptomes and splicesomes using massively parallel RNA sequencing (RNA-seq) has revealed that the extent of alternative splicing has been considerably underestimated (Filichkin et al. 2010). Evidence also suggests that many premRNAs undergo unproductive alternative splicing resulting in incorporation of in-frame premature termination codons. We have investigated alternative splicing in $C s C C D 2$ at three key developmental stages regarding crocetin biosynthesis and crocins accumulation (Moraga et al. 2009). Splice variants mainly accumulate in white and yellow stages, and we detected differences in the splice variants depending on the $C s C C D 2$ gene copy. In the $C s C C D 2 a$ the preferred retained introns were the introns 6, 8 and 9; whereas in the $C s C C D 2 b$ introns 2, 3 and 4 were the preferred retained ones. Perhaps the presence of intron 1 favours the recruitment of splicing factors for the more efficient splicing of introns 2, 3 and 4 in $C s C C D 4 a$. Further, the $C s C C D 2$ introns retained were not equally represented in the three analysed stages; introns 2, 6 and 9 were preferentially retained in transcripts identified in the orange stages, whereas introns 3 , 4 and 8 were preferentially retained in the yellow stages. Certain splicing signals (i.e., cis elements) could reside in the introns or junction sites of $C s C C D 2$. In accordance to this idea, $C s C C D 2$ splice-site sequences differ among them and from the consensus sequences obtained from the CCD1 monocot sequences. It has been suggested that weaker splice sites, the presence or absence of splicing regulators, RNA secondary structures, the exon/intron architecture, and the process of pre-mRNA synthesis itself are associated with intron retention (Hertel 2008). In addition, cis-regulatory elements are likely to play as well a crucial role in regulating intron retention by specific RNA-binding proteins and suggest a biological significance for this process in marking exons that are poised for alternative splicing (Sakabe and de Souza 2007). Alternative splicing has also been observed in $P S Y$, suggested to be a key regulatory step in carotenoid biosynthesis (Cazzonelli and Pogson 2010; Fu et al. 2014; Rodriguez-Suarez et al. 2011). PSY alternative splicing in wheat results in the generation of four different transcripts, being only one functional, thereby titrating the level of functional PSY (Howitt et al. 2009). This can be the case for $C s C C D 2$, the obtained data showed the presence of intron retention, which is much more evident in those tissues that do not accumulated crocins, where practically not functional $C s C C D 2$ transcripts without introns were detected.

\section{Promoter analysis}

Transcriptional activation of gene expression seems to be the major form of regulation of carotenoid biosynthesis in many fruits and flowers (Fraser and Bramley 2004; Hirschberg 2001). Bio-informatics analyses of the obtained sequence identified putative TATA and CAAT boxes in the promoter. In addition, several light-response motifs were identified in the promoter, e.g. G-box, G-Box, Ace, I-Box, GATA-motif, Sp1 and GTGGC-motif, providing the basis for the regulation of apocarotenogenic gene expression according to day length and other cues involved in the control of flower development in saffron (Molina et al. 2005b). At least one circadian regulatory cis-element was also identified in the promoter of $C s C C D 2$ and two regulatory elements associated with phase-specific transcript accumulation.

A number of studies showed that light controls carotenoid biosynthesis in different species during fruit ripening, flower and root development (Fuentes et al. 2012; Kishimoto et al. 2004; Liu et al. 2004; Stange et al. 2008; $\mathrm{Zhu}$ et al. 2002). Moreover, CCDl transcript levels displayed circadian regulation in petunia and Osmathus flowers (Baldermann et al. 2010; Simkin et al. 2004) suggesting that carotenoid modification is also regulated by light. In addition, an in silico analysis with Genevestigator (www.genevestigator.com) indicated that the four $C C D$ genes of Arabidopsis are not induced by light.

Other regulatory elements related with abiotic stress responses were identified in the promoter region such as a three HSE elements involved in heat stress responsiveness and three LTR elements involved in low-temperature responsiveness. While relative high temperatures are necessary for flower induction in saffron (during May-June), flower emergence and further stigma development in saffron required low temperature $\left(15-17^{\circ} \mathrm{C}\right)$ (SeptemberOctober) (Molina et al. 2005a). CsCCD2 expression is restricted to the stigma tissues (Rubio et al. 2008) and the presence of temperature response elements may help to coordinate $C s C C D 2$ expression and stigma development in saffron. While high temperatures repressed $\mathrm{CsCCD} 2$ expression, $C s C C D 2$ was up-regulated by low temperatures, and in plants growing in the field the highest $C s C C D 2$ expression levels were reached when the lowest temperatures were measured $\left(12-13^{\circ} \mathrm{C}\right)$. In addition, an $\mathrm{ABRE}$ element, which is responsive to $\mathrm{ABA}$ is present in the $C s C C D 2$ promoter and ABA signalling plays a vital role in plant stress responses, including cold (Wang et al. 2003).

The integration of expression profiles and promoter sequences can help to identify common and putative functionally relevant cis-acting elements (Ma and Bohnert 2007). Comparative bio-informatics studies on promoter 
regions of carotenoid genes may elucidate common binding motifs involved in carotenoid formation (Fraser and Bramley 2004). We therefore compared the isolated $C s C C D 2$ promoter sequence with the $C s L y c B 2 a$ promoter (Ahrazem et al. 2010a) using the Plant-CARE and PLACE databases. Both promoters contained several light response elements, at least one ABRE element, and a circadian regulatory motif. Furthermore, both promoters shared several domains that could represent putative cis-acting elements controlling the coordinated expression of these genes in the early developmental stages of the stigma.

\section{Regulation of $C s C C D 2$ expression}

We have observed that the steady-state transcript levels of $C s C C D 2$ are subjected to a daily rhythmic pattern of expression with higher expression levels during the night and at the time of lower temperatures. In addition, the same behaviour was observed for the chromoplast-specific genes $C s L y c B 2 a$ and $C s B C H 1$. The light/dark regulation of carotenoid biosynthesis has been investigated in red pepper, where all transcript levels of genes involved in the carotenoid biosynthesis decreased under dark conditions (Simkin et al. 2003b) and in tomato leaves where the phytoene desaturase and $\xi$-carotene desaturase genes increased just prior to the light period (Simkin et al. 2003a). In citrus, the transcript levels of genes encoding enzymes involved in carotenoid biosynthesis are affected by the light quality (Kato et al. 2004; Zhang et al. 2012). The transcript abundance of carotenogenic genes in Arabidopsis is controlled by light, and also clock controlled, with genes showing a peak during the night period (Covington et al. 2008). However, in contrast to the dawnphased transcript accumulation of carotenoid biosynthetic genes, a gene encoding a violaxanthin de-epoxidase in Arabidopsis leaves, showed the highest expression at subjective dusk (Covington et al. 2008). This antiphasic transcript accumulation pattern respect to the other carotenoid genes coincides well with the antagonistically activity of violaxanthin de-epoxidase, which acts recycling the carotenoid violaxanthin into compounds upstream of violaxanthin synthesis (Jahns et al. 2009). In all the analysed cases, the observed regulation of the carotenogenic genes is associated to the essential role that carotenoids play in the process of nonphotochemical quenching, which allows plants to quench excited chlorophyll and prevent oxidative damage under excessive light conditions. However, this is not the case for the biosynthesis of carotenoids in saffron stigma where carotenoid formation takes place in the absence of light (Moraga et al. 2009; Rubio et al. 2008), in the underground, as occurs in cassava (Henrique et al. 2007), sweetpotato (Teow et al. 2007) and carrots (Rodriguez-Concepcion and Stange 2013). In carrots, light prevents the differentiation of chromoplasts and modulates the expression of most carotenogenic genes while the absence of light contributes to the differentiation of chromoplasts and the accumulation of carotenoids. Our results showed that in fact darkness promotes higher accumulation of crocins and $C s C C D 2$ expression, while continuous light repressed $C s C C D 2$ expression. During the development of the stigma CsCCD2 expression drops in the stigma of buds and flowers that have already emerged to the light (Frusciante et al. 2014; Rubio et al. 2008), the same is observed for crocins, which content has been increased as the stigma develops in the underground (Moraga et al. 2009), showing that flower development in saffron is coordinated with apocarotenoid biosynthesis in the stigma tissue, as observed for other Crocus species (Ahrazem et al. 2015a), suggesting a highly interconnected regulatory network that coordinates flower development and apocarotenoid biosynthesis. Therefore, the control of nuclear gene expression in response to the developmental state of plastids should be critical for the synthesis and accumulation of crocins in the chromoplast by the activity of $C s C C D 2$. Based on the retrograde signalling concept in plastids, signals originating from the chromoplast might modulate the expression of the nuclear gene $C s C C D 2$. Interestingly, in the promoter of nuclear genes associated with this retrograde signalling the ACGT motif, and the core of both the light-responsive $\mathrm{G}$ box (CACGTG) and the ABA response element (ABRE) are over-represented (Koussevitzky et al. 2007), and all these elements are present in the promoter of $C s C C D 2$, that could be a clear target for the retrograde signal generated in the chromoplast that modulates $C s C C D 2$ expression.

Metabolites are the most likely candidates for retrograde signalling molecules and three apocarotenoids including $\mathrm{ABA}$ and $\beta$-cyclocitral, are conceived as putative retrograde signals (Estavillo et al. 2012; Leister 2012). $\beta$-cyclocitral is produced in saffron stigma in early developmental stages, from yellow to red, following an accumulation pattern similar to CsCCD2 expression (Moraga et al. 2009), and it could be considered as a putative signal molecule derived from the chromoplast responsible for $C s C C D 2$ activation (Fig. 7). In fact, CsCCD2 expression was activated by $\beta$-cyclocitral, although the involvement of other apocarotenoids generated by the activity of the different CCDs expressed in the saffron stigma cannot be excluded from this model (Ahrazem et al. 2010b; Rubio-Moraga et al. 2014a, b) (Fig. 7). Furthermore, because these apocarotenoids can affect major developmental processes (Avendano-Vazquez et al. 2014; Barbier et al. 2015) they can function as well as feedback signals responding to the state of organelle development. In fact, changes in organellar function are known to result in corresponding changes of at least some 


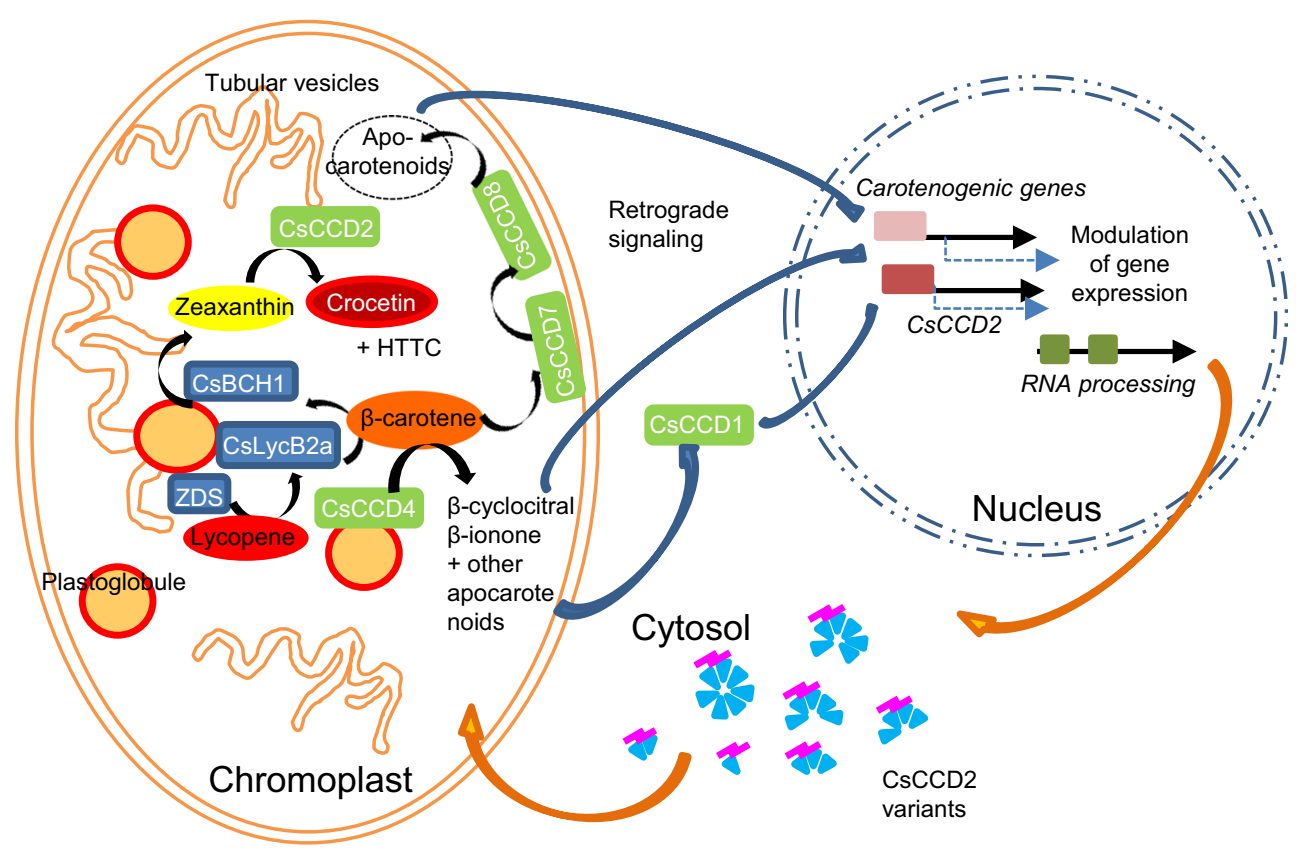

Fig. 7 Schematic representation of the putative retrograde signalling pathway from the chromoplast to the nucleus for crocetin accumulation and chromoplast development. Different kinds of apocarotenoids are produced by CCDs in the chromoplast of saffron stigma in a developmental-dependent way. Many of these apocarotenoids could diffuse through the chromoplast membranes into the

metabolite pool sizes, which define distinct metabolic states or metabolite signatures (Pfannschmidt 2010).

The control mechanism of gene regulation by these signals still mainly unknown (Estavillo et al. 2012), but recently it has been shown that a chloroplast retrograde signal regulate nuclear alternative splicing (Petrillo et al. 2014). Alternatively spliced genes are involved in a broad range of plant functions, such as signal transduction, growth and development, responses to stresses, the circadian clock, flowering time, metabolism and physiology (Kazan 2003). In addition, unproductive alternative splicing allows rapid and steep adjustments in mRNA levels, allowing the synchronization of physiological processes with periodic environmental changes (Filichkin et al. 2015; Filichkin and Mockler 2012; Sanchez et al. 2011). Certainly such a mechanism could be extended to other retrograde signalling pathways explaining the alternative splicing observed in $C s C C D 2$.

Acknowledgments This work was supported by the Spanish Ministerio de Economía y Competitividad (BIO2013-44239-R) and Dr. Ahrazem was funded by FPCYTCLM through the INCRECYT Programme. The laboratory participates in the IBERCAROT network (112RT0445)

Author contribution O.A. and L.G.-G. conceived the project, designed and supervised the experiments, analyzed the data, and cytosol and act directly as signals for gene expression modulation or could be further modified by CCD1. The resulting apocarotenoids may act as the inducers of gene expression modulation of carotenogenic genes, $C s C C D 2$ and other gene targets related to chromoplast biogenesis and homeostasis during flower development in saffron

wrote the article; A.R.-M., and R.C. performed most of the experiments; J.A. performed the treatments and crocins analyses.

\section{Compliance with ethical standards}

Conflict of interest The authors declare that they have no conflict of interest.

Open Access This article is distributed under the terms of the Creative Commons Attribution 4.0 International License (http://crea tivecommons.org/licenses/by/4.0/), which permits unrestricted use, distribution, and reproduction in any medium, provided you give appropriate credit to the original author(s) and the source, provide a link to the Creative Commons license, and indicate if changes were made.

\section{References}

Ahrazem O, Rubio-Moraga A, Lopez RC, Gomez-Gomez L (2010a) The expression of a chromoplast-specific lycopene beta cyclase gene is involved in the high production of saffron's apocarotenoid precursors. J Exp Bot 61:105-119

Ahrazem O, Trapero A, Gomez MD, Rubio-Moraga A, GomezGomez L (2010b) Genomic analysis and gene structure of the plant carotenoid dioxygenase 4 family: a deeper study in Crocus sativus and its allies. Genomics 96:239-250

Ahrazem O, Rubio-Moraga A, Jimeno ML, Gómez-Gómez L (2015a) Structural characterization of highly glucosylated crocins and regulation of their biosynthesis during flower development in Crocus. Front Plant Sci 6:971. doi:10.3389/fpls.2015.00971 
Ahrazem O, Rubio-Moraga A, Nebauer SG, Molina RV, GomezGomez L (2015b) Saffron: its phytochemistry, developmental processes, and biotechnological prospects. J Agric Food Chem 63:8751-8764

Ahrazem O, Rubio-Moraga A, Berman J, Capell T, Christou P, Zhu C, Gomez-Gomez L (2016) The carotenoid cleavage dioxygenase CCD2 catalysing the synthesis of crocetin in spring crocuses and saffron is a plastidial enzyme. New Phytol 209:650-663

Al-Babili S, Bouwmeester HJ (2015) Strigolactones, a novel carotenoid-derived plant hormone. Annu Rev Plant Biol 66:161-186

Auldridge ME, McCarty DR, Klee HJ (2006) Plant carotenoid cleavage oxygenases and their apocarotenoid products. Curr Opin Plant Biol 9:315-321

Avendano-Vazquez AO, Cordoba E, Llamas E, San Roman C, Nisar $\mathrm{N}$, De la Torre S, Ramos-Vega M, Gutierrez-Nava MD, Cazzonelli CI, Pogson BJ, Leon P (2014) An uncharacterized apocarotenoid-derived signal generated in zeta-carotene desaturase mutants regulates leaf development and the expression of chloroplast and nuclear genes in Arabidopsis. Plant Cell 26:2524-2537

Baldermann S, Kato M, Kurosawa M, Kurobayashi Y, Fujita A, Fleischmann P, Watanabe N (2010) Functional characterization of a carotenoid cleavage dioxygenase 1 and its relation to the carotenoid accumulation and volatile emission during the floral development of Osmanthus fragrans Lour. J Exp Bot 61:2967-2977

Barbier FF, Lunn JE, Beveridge CA (2015) Ready, steady, go! A sugar hit starts the race to shoot branching. Curr Opin Plant Biol $25: 39-45$

Brosius J (2003) The contribution of RNAs and retroposition to evolutionary novelties. Genetica 118:99-116

Castillo R, Fernandez JA, Gomez-Gomez L (2005) Implications of carotenoid biosynthetic genes in apocarotenoid formation during the stigma development of Crocus sativus and its closer relatives. Plant Physiol 139:674-689

Cazzonelli CI, Pogson BJ (2010) Source to sink: regulation of carotenoid biosynthesis in plants. Trends Plant Sci 15:266-274

Covington MF, Maloof JN, Straume M, Kay SA, Harmer SL (2008) Global transcriptome analysis reveals circadian regulation of key pathways in plant growth and development. Genome Biol 9:R130

Cunningham FX, Gantt E (1998) Genes and enzymes of carotenoid biosynthesis in plants. Annu Rev Plant Physiol Plant Mol Biol 49:557-583

de Souza S, Long M, Schoenbach L, Roy SW, Gilbert W (1996) Intron positions correlate with module boundaries in ancient proteins. Proc Natl Acad Sci USA 93:5

Duret L (2001) Why do genes have introns? Recombination might add a new piece to the puzzle. Trends Genet 17:172-175

Estavillo GM, Chan KX, Phua SY, Pogson BJ (2012) Reconsidering the nature and mode of action of metabolite retrograde signals from the chloroplast. Front Plant Sci 3:300

Filichkin SA, Mockler TC (2012) Unproductive alternative splicing and nonsense mRNAs: a widespread phenomenon among plant circadian clock genes. Biol Direct 7:20

Filichkin SA, Priest HD, Givan SA, Shen R, Bryant DW, Fox SE, Wong WK, Mockler TC (2010) Genome-wide mapping of alternative splicing in Arabidopsis thaliana. Genome Res 20:45-58

Filichkin SA, Cumbie JS, Dharmawardhana P, Jaiswal P, Chang JH, Palusa SG, Reddy AS, Megraw M, Mockler TC (2015) Environmental stresses modulate abundance and timing of alternatively spliced circadian transcripts in Arabidopsis. Mol Plant 8:207-227
Fraser PD, Bramley PM (2004) The biosynthesis and nutritional uses of carotenoids. Prog Lipid Res 43:228-265

Frusciante S, Diretto G, Bruno M, Ferrante P, Pietrella M, PradoCabrero A, Rubio-Moraga A, Beyer P, Gomez-Gomez L, AlBabili S, Giuliano G (2014) Novel carotenoid cleavage dioxygenase catalyzes the first dedicated step in saffron crocin biosynthesis. Proc Natl Acad Sci U S A 111:12246-12251

Fu X, Feng C, Wang C, Yin X, Lu P, Grierson D, Xu C, Chen K (2014) Involvement of multiple phytoene synthase genes in tissue- and cultivar-specific accumulation of carotenoids in loquat. J Exp Bot 65:4679-4689

Fuentes P, Pizarro L, Moreno JC, Handford M, Rodriguez-Concepcion M, Stange C (2012) Light-dependent changes in plastid differentiation influence carotenoid gene expression and accumulation in carrot roots. Plant Mol Biol 79:47-59

Gómez-Gómez L, Moraga-Rubio A, Ahrazem O (2010) Understanding carotenoid metabolism in saffron stigmas: unravelling aroma and colour formation. In: Teixeira da Silva JA (ed) Functional plant science adn biotechnology. Glob Sci Books, UK, pp 56-63

Grilli-Caiola MG, Canini A (2004) Ultrastructure of chromoplasts and other plastids in Crocus sativus L. (Iridaceae). Plant Biosyst 138:9

Harmer SL, Kay SA (2005) Positive and negative factors confer phase-specific circadian regulation of transcription in Arabidopsis. Plant Cell 17:1926-1940

Henrique CM, Teofilo RF, Sabino L, Ferreira MM, Cereda MP (2007) Classification of cassava starch films by physicochemical properties and water vapor permeability quantification by FTIR and PLS. J Food Sci 72:E184-E189

Hertel KJ (2008) Combinatorial control of exon recognition. J Biol Chem 283:1211-1215

Higo K, Ugawa Y, Iwamoto M, Korenaga T (1999) Plant cis-acting regulatory DNA elements (PLACE) database: 1999. Nucleic Acids Res 27:297-300

Hirschberg J (2001) Carotenoid biosynthesis in flowering plants. Curr Opin Plant Biol 4:210-218

Howitt CA, Cavanagh CR, Bowerman AF, Cazzonelli C, Rampling L, Mimica JL, Pogson BJ (2009) Alternative splicing, activation of cryptic exons and amino acid substitutions in carotenoid biosynthetic genes are associated with lutein accumulation in wheat endosperm. Funct Integr Genomics 9:363-376

Ilg A, Bruno M, Beyer P, Al-Babili S (2014) Tomato carotenoid cleavage dioxygenases $1 \mathrm{~A}$ and $1 \mathrm{~B}$ : relaxed double bond specificity leads to a plenitude of dialdehydes, mono-apocarotenoids and isoprenoid volatiles. FEBS Open Bio 4:584-593

Jahns P, Latowski D, Strzalka K (2009) Mechanism and regulation of the violaxanthin cycle: the role of antenna proteins and membrane lipids. Biochim Biophys Acta 1787:3-14

Jain M, Srivastava PL, Verma M, Ghangal R, Garg R (2016) De novo transcriptome assembly and comprehensive expression profiling in Crocus sativus to gain insights into apocarotenoid biosynthesis. Sci Rep 6:22456

Jeong YM, Mun JH, Lee I, Woo JC, Hong CB, Kim SG (2006) Distinct roles of the first introns on the expression of Arabidopsis profilin gene family members. Plant Physiol 140:196-209

Kaessmann H, Vinckenbosch N, Long M (2009) RNA-based gene duplication: mechanistic and evolutionary insights. Nat Rev Genet 10:19-31

Kato M, Ikoma Y, Matsumoto H, Sugiura M, Hyodo H, Yano M (2004) Accumulation of carotenoids and expression of carotenoid biosynthetic genes during maturation in citrus fruit. Plant Physiol 134:824-837

Kazan K (2003) Alternative splicing and proteome diversity in plants: the tip of the iceberg has just emerged. Trends Plant Sci $8: 468-471$ 
Kelley LA, Mezulis S, Yates CM, Wass MN, Sternberg MJ (2015) The Phyre2 web portal for protein modeling, prediction and analysis. Nat Protoc 10:845-858

Kishimoto S, Maoka T, Nakayama M, Ohmiya A (2004) Carotenoid composition in petals of chrysanthemum (Dendranthema grandiflorum (Ramat.) Kitamura). Phytochemistry 65:2781-2787

Kloer DP, Schulz GE (2006) Structural and biological aspects of carotenoid cleavage. Cell Mol Life Sci 63:2291-2303

Koussevitzky S, Nott A, Mockler TC, Hong F, Sachetto-Martins G, Surpin M, Lim J, Mittler R, Chory J (2007) Signals from chloroplasts converge to regulate nuclear gene expression. Science 316:715-719

Leister D (2012) Retrograde signaling in plants: from simple to complex scenarios. Front Plant Sci 3:135

Lescot M, Dehais P, Thijs G, Marchal K, Moreau Y, Van de Peer Y, Rouze P, Rombauts S (2002) PlantCARE, a database of plant cis-acting regulatory elements and a portal to tools for in silico analysis of promoter sequences. Nucleic Acids Res 30:325-327

Liu Y, Roof S, Ye Z, Barry C, van Tuinen A, Vrebalov J, Bowler C, Giovannoni J (2004) Manipulation of light signal transduction as a means of modifying fruit nutritional quality in tomato. Proc Natl Acad Sci USA 101:9897-9902

Ma S, Bohnert HJ (2007) Integration of Arabidopsis thaliana stressrelated transcript profiles, promoter structures, and cell-specific expression. Genome Biol 8:R49

Marais G, Nouvellet P, Keightley PD, Charlesworth B (2005) Intron size and exon evolution in Drosophila. Genetics 170:481-485

Mastrangelo AM, Marone D, Laido G, De Leonardis AM, De Vita P (2012) Alternative splicing: enhancing ability to cope with stress via transcriptome plasticity. Plant Sci 185-186:40-49

McWilliam H, Li W, Uludag M, Squizzato S, Park YM, Buso N, Cowley AP, Lopez R (2013) Analysis tool web services from the EMBL-EBI. Nucleic Acids Res 41:W597-W600

Messing SA, Gabelli SB, Echeverria I, Vogel JT, Guan JC, Tan BC, Klee HJ, McCarty DR, Amzel LM (2010) Structural insights into maize viviparous14, a key enzyme in the biosynthesis of the phytohormone abscisic acid. Plant Cell 22:2970-2980

Molina R, Valero M, Navarro Y, Guardiola JL, Garcia-Luis A (2005a) Temperature effects on flower formation in saffron (Crocus sativus L.). Sci Hortic 103:361-379

Molina RV, Valero M, Navarro Y, Garcia-Luis A, Guardiola JL (2005b) Low temperature storage of corms extends the flowering season of saffron (Crocus sativus L.). J Hortic Sci Biotechnol 80:319-326

Moraga AR, Nohales PF, Perez JA, Gomez-Gomez L (2004) Glucosylation of the saffron apocarotenoid crocetin by a glucosyltransferase isolated from Crocus sativus stigmas. Planta 219:955-966

Moraga AR, Rambla JL, Ahrazem O, Granell A, Gomez-Gomez L (2009) Metabolite and target transcript analyses during Crocus sativus stigma development. Phytochemistry 70:1009-1016

Mun JH, Lee SY, Yu HJ, Jeong YM, Shin MY, Kim H, Lee I, Kim SG (2002) Petunia actin-depolymerizing factor is mainly accumulated in vascular tissue and its gene expression is enhanced by the first intron. Gene 292:233-243

Nakagawa S, Niimura Y, Gojobori T, Tanaka H, Miura K (2008) Diversity of preferred nucleotide sequences around the translation initiation codon in eukaryote genomes. Nucleic Acids Res 36:861-871

Ner-Gaon H, Halachmi R, Savaldi-Goldstein S, Rubin E, Ophir R, Fluhr R (2004) Intron retention is a major phenomenon in alternative splicing in Arabidopsis. Plant J 39:877-885

Petrillo E, Godoy Herz MA, Fuchs A, Reifer D, Fuller J, Yanovsky MJ, Simpson C, Brown JW, Barta A, Kalyna M, Kornblihtt AR (2014) A chloroplast retrograde signal regulates nuclear alternative splicing. Science 344:427-430
Pfannschmidt T (2010) Plastidial retrograde signalling a true "plastid factor" or just metabolite signatures? Trends Plant Sci 15:8

Piechulla B, Merforth N, Rudolph B (1998) Identification of tomato Lhc promoter regions necessary for circadian expression. Plant Mol Biol 38:655-662

Plesse B, Criqui MC, Durr A, Parmentier Y, Fleck J, Genschik P (2001) Effects of the polyubiquitin gene Ubi. U4 leader intron and first ubiquitin monomer on reporter gene expression in Nicotiana tabacum. Plant Mol Biol 45:655-667

Poliakov E, Gentleman S, Cunningham FX Jr, Miller-Ihli NJ, Redmond TM (2005) Key role of conserved histidines in recombinant mouse beta-carotene $15,15^{\prime}$-monooxygenase-1 activity. J Biol Chem 280:29217-29223

Ramel F, Birtic S, Ginies C, Soubigou-Taconnat L, Triantaphylides C, Havaux M (2012) Carotenoid oxidation products are stress signals that mediate gene responses to singlet oxygen in plants. Proc Natl Acad Sci USA 109:5535-5540

Reddy AS, Marquez Y, Kalyna M, Barta A (2013) Complexity of the alternative splicing landscape in plants. Plant Cell 25:3657-3683

Redmond TM, Poliakov E, Yu S, Tsai JY, Lu Z, Gentleman S (2005) Mutation of key residues of RPE65 abolishes its enzymatic role as isomerohydrolase in the visual cycle. Proc Natl Acad Sci USA 102:13658-13663

Rodriguez-Concepcion M, Stange C (2013) Biosynthesis of carotenoids in carrot: an underground story comes to light. Arch Biochem Biophys 539:110-116

Rodriguez-Suarez C, Atienza SG, Piston F (2011) Allelic variation, alternative splicing and expression analysis of Psy1 gene in Hordeum chilense Roem. et Schult. PLoS ONE 6:e19885

Rose AB, Last RL (1997) Introns act post-transcriptionally to increase expression of the Arabidopsis thaliana tryptophan pathway gene PAT1. Plant J 11:455-464

Rubio Moraga A, Ahrazem O, Rambla JL, Granell A, Gomez Gomez L (2013) Crocins with high levels of sugar conjugation contribute to the yellow colours of early-spring flowering crocus tepals. PLoS ONE 8:e71946

Rubio A, Rambla JL, Santaella M, Gomez MD, Orzaez D, Granell A, Gomez-Gomez L (2008) Cytosolic and plastoglobule-targeted carotenoid dioxygenases from Crocus sativus are both involved in beta-ionone release. J Biol Chem 283:24816-24825

Rubio-Moraga A, Trapero A, Ahrazem O, Gomez-Gomez L (2010) Crocins transport in Crocus sativus: the long road from a senescent stigma to a newborn corm. Phytochemistry 71:1506-1513

Rubio-Moraga A, Ahrazem O, Perez-Clemente RM, Gomez-Cadenas A, Yoneyama K, Lopez-Raez JA, Molina RV, Gomez-Gomez L (2014a) Apical dominance in saffron and the involvement of the branching enzymes CCD7 and CCD8 in the control of bud sprouting. BMC Plant Biol 14:171

Rubio-Moraga A, Rambla JL, Fernandez-de-Carmen A, TraperoMozos A, Ahrazem O, Orzaez D, Granell A, Gomez-Gomez L (2014b) New target carotenoids for CCD4 enzymes are revealed with the characterization of a novel stress-induced carotenoid cleavage dioxygenase gene from Crocus sativus. Plant Mol Biol $86: 555-569$

Sakabe NJ, de Souza SJ (2007) Sequence features responsible for intron retention in human. BMC Genom 8:59

Sanchez SE, Petrillo E, Kornblihtt AR, Yanovsky MJ (2011) Alternative splicing at the right time. RNA Biol 8:954-959

Schwartz SH, Tan BC, Gage DA, Zeevaart JA, McCarty DR (1997) Specific oxidative cleavage of carotenoids by VP14 of maize. Science 276:1872-1874

Schwartz SH, Qin X, Zeevaart JA (2001) Characterization of a novel carotenoid cleavage dioxygenase from plants. J Biol Chem 276:25208-25211 
Simkin AJ, Laboure AM, Kuntz M, Sandmann G (2003a) Comparison of carotenoid content, gene expression and enzyme levels in tomato (Lycopersicon esculentum) leaves. Z Naturforsch C 58:371-380

Simkin AJ, Zhu C, Kuntz M, Sandmann G (2003b) Light-dark regulation of carotenoid biosynthesis in pepper (Capsicum аппиит) leaves. J Plant Physiol 160:439-443

Simkin AJ, Underwood BA, Auldridge M, Loucas HM, Shibuya K, Schmelz E, Clark DG, Klee HJ (2004) Circadian regulation of the PhCCD1 carotenoid cleavage dioxygenase controls emission of beta-ionone, a fragrance volatile of petunia flowers. Plant Physiol 136:3504-3514

Staiger D, Green R (2011) RNA-based regulation in the plant circadian clock. Trends Plant Sci 16:517-523

Stange C, Fuentes P, Handford M, Pizarro L (2008) Daucus carota as a novel model to evaluate the effect of light on carotenogenic gene expression. Biol Res 41:289-301

Sui X, Kiser PD, Lintig J, Palczewski K (2013) Structural basis of carotenoid cleavage: from bacteria to mammals. Arch Biochem Biophys 539:203-213

Takahashi Y, Moiseyev G, Chen Y, Ma JX (2005) Identification of conserved histidines and glutamic acid as key residues for isomerohydrolase activity of RPE65, an enzyme of the visual cycle in the retinal pigment epithelium. FEBS Lett 579:5414-5418

Teow CC, Truong V-D, McFeeters RF, Thompson RL, Pecota KV, Yencho GC (2007) Antioxidant activities, phenolic and $\beta$ carotene contents of sweetpotato genotypes with varying flesh colours. Food Chem 103:9

Walter MH, Strack D (2011) Carotenoids and their cleavage products: biosynthesis and functions. Nat Prod Rep 28(4):663-692

Wang W, Vinocur B, Altman A (2003) Plant responses to drought, salinity and extreme temperatures: towards genetic engineering for stress tolerance. Planta 218:1-14

Winterhalter P, Rouseff R (2001) Carotenoid derived aroma compounds. American Chemical Society, Washington

Zhang L, Ma G, Kato M, Yamawaki K, Takagi T, Kiriiwa Y, Ikoma Y, Matsumoto H, Yoshioka T, Nesumi H (2012) Regulation of carotenoid accumulation and the expression of carotenoid metabolic genes in citrus juice sacs in vitro. $\mathrm{J}$ Exp Bot 63:871-886

Zhu C, Yamamura S, Koiwa H, Nishihara M, Sandmann G (2002) cDNA cloning and expression of carotenogenic genes during flower development in Gentiana lutea. Plant Mol Biol 48:277-285 